EUROPEAN CENTRAL BANK

WORKING PAPER SERIES

N0. 387 / AUGUST 2004

\title{
HORIZONTAL AND VERTICAL INTEGRATION IN SECURITIES \\ TRADING AND SETTLEMENT
}

by Jens Tapking and Jing Yang

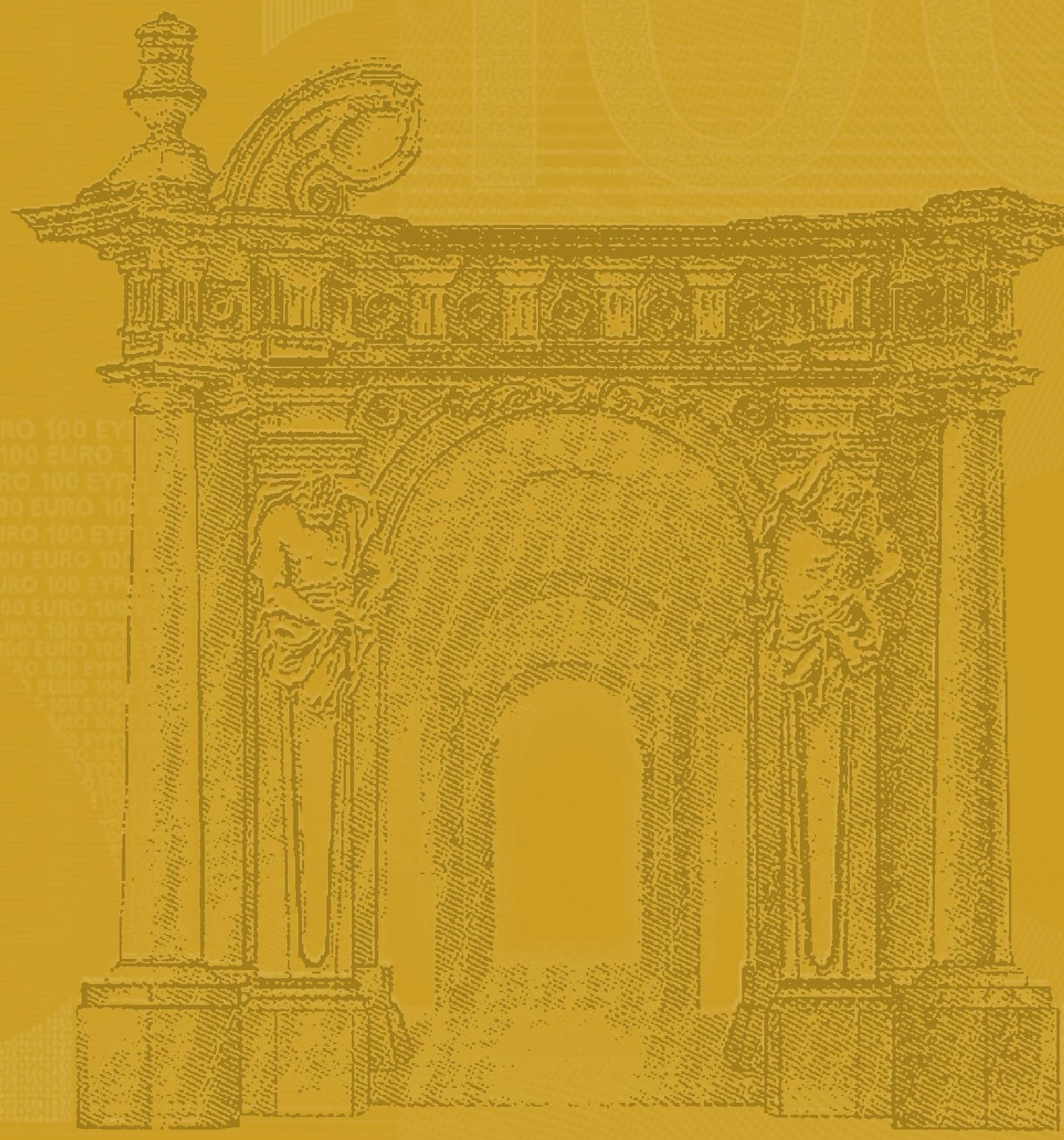




\title{
HORIZONTAL AND VERTICAL INTEGRATION IN SECURITIES TRADING AND SETTLEMENT
}

\author{
by Jens Tapking ${ }^{2}$ \\ and Jing Yang ${ }^{3}$
}

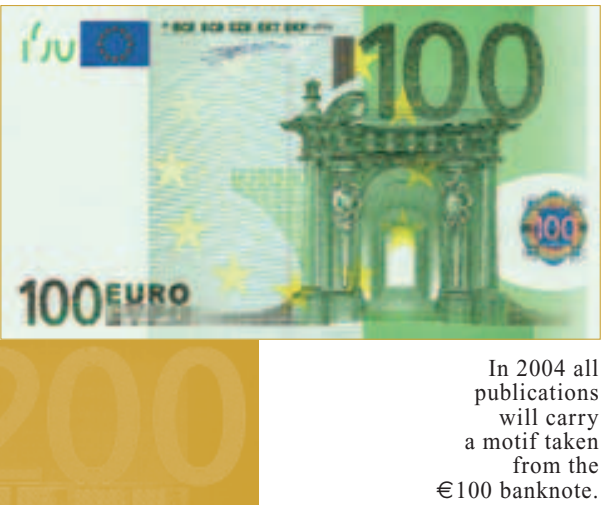

This paper can be downloaded without charge from http://www.ecb.int or from the Social Science Research Network electronic library at http://ssrn.com/abstract_id $=576025$. 


\section{드 European Central Bank, 2004}

\section{Address}

Kaiserstrasse 29

60311 Frankfurt am Main, Germany

Postal address

Postfach 160319

60066 Frankfurt am Main, Germany

Telephone

+496913440

\section{Internet}

http://www.ecb.int

Fax

+496913446000

Telex

411144 ecb d

All rights reserved.

Reproduction for educational and noncommercial purposes is permitted provided that the source is acknowledged.

The views expressed in this paper do not necessarily reflect those of the European Central Bank.

The statement of purpose for the ECB Working Paper Series is available from the ECB website, http://www.ecb.int.

ISSN 1561-0810 (print)

ISSN 1725-2806 (online) 


\section{CONTENTS}

Abstract 4

Non-technical summary 5

1 Introduction 7

2 The model 12

3 Stock market equilibrium $\quad$ I5

4 Transaction price equilibrium $\quad$ I7

4.1 Payoff functions $\quad 17$

4.2 Complete separation 18

4.3 Vertical integration 20

4.4 Horizontal integration of CSDs 2I

5. Welfare analysis 23

5.1 Net social benefit function and welfare maximum

5.2 Comparison of social benefit for different industry structures

6 Concluding remarks 26

7 Appendix A 27

8 Appendix B 3।

References 40

European Central Bank working paper series $\quad 42$ 


\begin{abstract}
This paper addresses a very European issue, the consolidation of securities trading and settlement infrastructures. In a two-country model, we analyze welfare implications of different types of consolidation. We find that horizontal integration of settlement systems is better than vertical integration of exchanges and settlement systems, but vertical integration is still better than no consolidation. These findings have clear policy implications with regards to the highly fragmented European securities infrastructure.

Keywords: Securities trading and settlement, vertical and horizontal integration, substitutes and complements.

JEL Classifications: G21, G15, L13.
\end{abstract}




\section{Non-technical summary}

Securities trading and securities settlement are essential parts of any securities transaction. Trading is the process that results in an agreement between a seller and a buyer to exchange securities for funds. Settlement refers to the actual transfer of securities from the seller to the buyer and the transfer of the funds from the buyer to the seller. Trading is often carried out on securities exchanges while settlement of on-exchange trades takes place in entities called central securities depositories (CSDs).

In the European Union, the securities trading and settlement infrastructure is highly fragmented. There are over 20 national exchanges and about as many central securities depositories (CSDs) in the EU. Market participants, central banks and regulators agree that consolidation is desirable. However, there is little agreement on what kind of consolidation would be optimal. Some people prefer vertical integration, i.e. mergers of exchanges with CSDs. Others favour horizontal integration of different exchanges or different CSDs.

In this paper, we try to shed light on the pros and cons of the different types of consolidation in a theoretical two-country model. There is an exchange and a CSD in each country. Investors can buy and sell securities on both exchanges. All trades executed on a given exchange are settled in the CSD of the same country. This reflects the current practice in all major markets. Hence, before a security held in the CSD of country 1 can be offered on the exchange of country 2, it has to be transferred to the CSD in country 2. This transfer is carried out through a so-called link, technologically a communication line between the two CSDs. A link transfer requires the services of both CSDs. One CSD has to release the securities and the other CSD has to take them under custody.

We start from a general observation that has been well established in industrial economics. From an economic welfare perspective, two goods that are substitutes should be supplied by different decision makers while two complements should be supplied by a single decision maker. On the basis of this observation, we argue as follows. The link services of the two CSDs are complements since each securities transfer from one to the other CSD requires both services. Furthermore, the link service of one CSD and the settlement service of the other CSD are complements since transferring securities from one to the other country makes sense only if these securities are afterwards traded and thus settled in the other country. The two CSDs should therefore be operated by the same decision maker (horizontal integration of CSDs). 
However, this argumentation is valid only if the operating costs of the link are low enough to allow the cross-border transfer of securities at reasonable costs. If the link is too expensive, a horizontal integration of the CSDs is desirable only if it reduces these link operating costs significantly. If it does not reduce these costs, a vertical integration of the exchange and the CSD in each country is preferable. This is because trading and settlement in a given country are also complements.

Furthermore, if there is no demand for foreign securities, there is also no demand for link transfers regardless of whether the link operating costs are high or low. In this case, the link has no significance and the above argument in favour of horizontal integration of the CSDs is again not valid. Instead we again find that a vertical integration of the exchange and the CSD in each country is preferable as trading and settlement in a given country are complements. 


\section{Introduction}

The European securities trading and settlement infrastructure is highly fragmented. There are over 20 national exchanges and about as many central securities depositories (CSDs) in the EU. Market participants, central banks and regulators agree that consolidation is desirable. However, there is little agreement on what kind of consolidation would be optimal. Some people prefer vertical integration, i.e. mergers of exchanges with CSDs (and clearing houses). Others favour horizontal integration of different exchanges or different CSDs. In this paper, we try to shed some light on the pros and cons of the different types of consolidation in a theoretical model.

In practice, all kinds of integration have been taking place in recent years. In Italy and in a similar way in Germany, the exchange and the CSD have been merged to form a so-called vertical silo. The merger of the exchanges of France, the Netherlands, Belgium and Portugal have created Euronext. The CSDs of France, the Netherlands, the UK and Belgium have been merged into Euroclear Group.

Securities exchanges and CSDs play essential roles in all major securities markets. Exchanges help to match buyers and sellers of securities. CSDs are central store houses for securities. In most countries, there is only one CSD and almost all securities issued under the country's legislation are stored there for their entire life - as physical papers or increasingly often electronically. Furthermore, CSDs maintain records establishing ownership of securities. Major financial institutions have securities accounts with the CSD and the account balances indicate the securities owned by the respective financial institution (or its direct or indirect clients). Finally, CSDs act as major settlement service providers: they organize the transfer of securities from a seller to a buyer. If one financial institution sells securities to another, the transaction is settled by book entries in the book of the CSD: The seller's securities account with the CSD is debited and the buyer's securities account is credited.

Exchanges and CSDs cooperate closely. Most exchanges use for reasons of costs or for legal reasons only one CSD to settle all trades executed on the exchange. All members of the exchange have to have (directly or via an intermediary) securities accounts with that CSD. Whenever two exchange members - a seller and a buyer - are matched on the exchange, the CSD receives automatically from the exchange the instructions to debit the seller's and to credit the buyer's securities account. This process is called straight through processing (STP).

Special problems arise in case of cross-listed securities if the two exchanges on which the securities are listed use different CSDs for settlement. Assume that an exchange $A$ uses only CSD $A$ and another 
exchange $B$ uses only CSD $B$. An investor may wish to sell on exchange $B$ securities held on his account with CSD $A$. Before he can do that, the securities have to be transferred from CSD $A$ to CSD $B$. For this purpose, CSDs maintain so-called (direct or indirect) links. Only after the securities have been credited to an account with CSD $B$, they can be sold on exchange $B$.

In this paper, we analyze the interactions between exchanges and CSDs in a two-country model. There is an exchange and a CSD in both countries. There are two types of securities, country $A$ securities and country $B$ securities. There are two types of investors, country $A$ and country $B$ investors. Initially, all country $A$ securities are held by country $A$ investors on accounts with CSD $A$ and all country $B$ securities are held by country $B$ investors with CSD $B$. Initially, all investors are members of their home exchange and CSD, but not of the foreign exchange and CSD. All securities are listed on both exchanges. All trades executed on exchange $A$ must be settled in CSD $A$ and all trades executed on exchange $B$ must be settled in CSD $B$. The two CSDs maintain a link so that securities can be transferred from one CSD to the other. Country $A$ investors want to buy $B$ securities and country $B$ investors want to buy $A$ securities, i.e. due to investors' preferences, only trades between investors from different countries are possible. ${ }^{1}$

There are two ways to initiate transactions for example between a country $A$ investor who wants to sell security $A$ and a country $B$ investor who wants to buy security $A$. Firstly, the $A$ investor offers the securities on exchange $A$ and the $B$ investor orders them on exchange $A$. Settlement takes place in CSD $A$ and the link is not used. This is relatively costly for the $B$ investor who needs to become a (directly or indirectly through an intermediary) member of exchange $A$ and CSD $A$. Secondly, the $A$ investor transfers the securities through the link from CSD $A$ to CSD $B$ and then offers them on exchange $B$ while the $B$ investor orders them on exchange $B$. This is costly for the $A$ investor who needs to transfer his securities through the link and must become a (direct or indirect) member of exchange $B$ and CSD $B$.

Link transfers must be carried out jointly by the two CSDs. A crucial exogenous parameter of the model is the operating costs of the CSDs for providing the link service. Each CSD sets a price the investor has to pay for this service. Furthermore, each exchange sets a price for the execution of trades and each CSD sets a price for the settlement of

\footnotetext{
${ }^{1}$ This is a strong assumption. However, in section 6 , we note the effects of including investors' demand for home securities.
} 
on-exchange trades. All four service providers are operated by profit maximizing firms. ${ }^{2}$

We analyze four different industry structures: (1) Under complete separation (CS), all four service providers are operated by different independent firms and set their prices independently. (2) Under vertical integration (VI), the exchange and the CSD in both countries are operated by the same firm and thus coordinate their price setting. (3) Under horizontal integration of the CSDs, both CSDs are operated by the same firm. The exchanges are operated independently. We distinguish two stages of horizontal integration: (a) Purely legal integrations (LHI): Though the CSDs are operated by the same firm, they are technologically still different systems. The transfer of securities through the link entails the same operating costs for the CSDs as under CS and VI. But the CSDs set their prices for the link transfer as well as for the settlement of on-exchange trades in a coordinated way. (b) Technical integration (THI): Both CSDs are technologically merged into one system so that a transfer of securities from one to another CSD does not entail any operating costs so that the operating costs of the link are zero.

Horizontal integration of CSDs may indeed always lead eventually to THI. However, analyzing LHI is still not redundant since it helps to distinguish two effects of the transition from CS to THI. This is a pure competition effect illustrated by the transition from CS to LHI. And a cost reduction effect illustrated by the transition from LHI to THI. Any kind of merger may have these two effects. This positive cost reduction effect may however be outweighed by a negative competition effect. Analyzing LHI as an intermediate step in the transition from CS to THI helps to distinguish these two effects of horizontal integration of CSDs.

A welfare comparison of the four industry structures is the center of our attention. The results of this comparison are strikingly simple: VI and LHI entail a (weakly) higher welfare then CS. That is, the competition effects of the transition from CS to LHI and from CS to VI are positive. If the link operating costs under CS, VI and LHI exceed a certain threshold, then VI entails a higher welfare then LHI so that the competition effect is greater in the transition to VI than in the transition to LHI. If the operating costs of the link under CS, VI and LHI are small than this threshold, then LHI entails a higher welfare then VI, i.e. the competition effect is greater in a transition to LHI. However, THI always entails the highest economic welfare of all four structures. In other words, even if the competition effect of a transition from CS to VI

\footnotetext{
${ }^{2}$ Some CSDs and exchanges are user owned. In these cases, one may argue that the assumption of profit maximization is not realistic. However, many CSDs and exchanges are organised as profit maximising entities.
} 
is greater than the competition effect of a transition to THI, the overall welfare improvement is still greatest in case of a transition to THI due to its cost reduction effect.

Before we explain the economic reasons for these results, it is helpful to recall a finding from basic industrial economics. ${ }^{3}$ Consider a standard Bertrand duopoly. In this setting, a merger of the two firms would decrease the economic welfare if the outputs of the firms are substitutes (provided that the merger does not reduce production costs). However, if the outputs are complements, then the merger would increase the welfare. The reason is the following: If two firms produce substitutes and the price of both firms is relatively high, then one firm can easily attract more demand by reducing its price a bit and boost up its profit. In equilibrium, both firms therefore set relatively low prices. If the firms instead produce (perfect) complements, then the demand at both firms depends on the sum of the prices of the two goods. Tourists for example consider the sum of the prices for the flight to a holiday destination and for the accommodation there. If the flight is cheap, they have high demand for hotel rooms even if these are relatively expensive. If now both firms set a relatively low price, one firm would not lose too much demand even if it increases its price significantly so that a higher price would result in a higher profit. In equilibrium, both firms therefore set relatively high prices. However, if now both firms merge and the new entity reduces the prices of the two complements, its profit would increase. Thus, the sum of the prices of the two complements would be lower if the two firms are vertically integrated.

Looking again on our model, we find that the exchange and the CSD of the same country offer perfect complements since trading on the exchange requires settlement in the CSD. This is why VI entails a higher welfare then CS. Now compare LHI and VI. Firstly note that (trading and) settlement in country $A$ and (trading and) settlement in country $B$ are substitutes. However, the link service provided by CSD $A$ and the link service provided by CSD $B$ are perfect complements. From that perspective, it is not immediately clear whether LHI or VI leads to a higher welfare. The reason why VI leads to a higher welfare than LHI if the link operating costs are high is simple. In this case, transferring securities through the link is too costly, i.e. the link is not used and securities are always traded where they are initially held. Thus, the CSDs in fact do not compete at all, neither in substitutes nor in complements. CS and LHI now lead exactly to the same equilibrium. However, VI leads to lower prices than CS and LHI and thus to a higher welfare because the exchange and the CSD of the same country offer

\footnotetext{
${ }^{3}$ See for example Tirole (1988) and Shy (1996).
} 
perfect complements. The reason why LHI leads to a higher welfare than VI if the link operating costs are low is a bit more complex and will be discussed in detail later. ${ }^{4}$

Finally, it is clear that THI leads to a higher welfare than LHI due to cost reductions. Thus, it is clear that THI is the best if the link operating costs are low since LHI is better than CS and VI in this case. However, if the link operating costs are high, then LHI is not better anymore than VI. But now, the cost reduction effect of THI is even more significant and THI is still better than all other industry structures.

Our findings have obvious implications for the policy discussion on what kind of consolidation may be most desirable for the European securities trading and settlement infrastructure. However, it is important to draw attention to two important limitations of our model. Firstly, we assume that the exchanges cannot choose which CSD they use. Each exchange has to settle on the CSD located in the exchange's country. This assumption clearly reduces the potential competition between the two CSDs significantly. If under CS, the CSDs were forced to compete with each other for the exchanges, then any type of horizontal integration of the CSDs may result in a negative competition effect. Currently, national exchanges are to a large extent bound to use exclusively the respective national CSD so that our assumption seems to be realistic enough. However, this may change at some point and it would be interesting to analyze the implications of such a change. Secondly we do not allow for OTC trading, i.e. assume that trading exclusively takes place on an exchange. Though this may appear realistic for equities, it is less realistic for bonds.

There is a large body of literature on vertical integration. An overview is in Perry (1989). Most applications of the theory of vertical integration are on network industries in which a monopolistic upstream firm (supplier of a network) produces an essential input for several competing downstream firms (users of the network). The main issue is the implications of a vertical merger of the upstream firm with one of the downstream firms. A prominent example is Vickers (1995). However, our study largely differs from this literature in the following aspects. There is no analogy of downstream/upstream firms in a trading and settlement system. Exchange do not receive services from and do not make payments to CSDs and the other way round. Furthermore, there is only one upstream firm in network industries while we have two exchanges and two CSDs in our model.

Another body of literature looks at competition among interconnected networks like two operator of mobile phone networks. See for

\footnotetext{
${ }^{4}$ See the two paragraphs after proposition 7 .
} 
examples Laffont, Rey and Tirole (1996a and 1996b) and Laffont and Tirole (1996). The situation analyzed by this literature somehow resembles the competition between two CSDs connected by a link. However, the literature on competition among interconnected networks focuses mainly on access price regulation while vertical integration is not an issue.

There is some literature on competition, cooperation and consolidation of securities exchanges. Examples are Domowitz (1995) and Shy and Tarkka (2001). A general discussion of competition among exchanges with a special view to Europe is Di Noia (1998). In this type of literature, exchanges are often considered as networks and consolidation of different networks as a way to pool liquidity in one place. ${ }^{5}$ There is currently very little literature on competition and consolidation of different settlement service providers. Examples are the empirical paper by Schmiedel, Malkamaki and Tarkka (2002), the theoretical work of Holthausen and Tapking (2003), Kauko (2003) and Koeppl and Monnet (2003). Kauko (2003) is related to our paper in that it looks at links as devices that create competition between CSDs. Koeppl and Monnet (2003) is to our knowledge the only other paper that looks at exchanges and CSDs in one model. They show in a two-country model with an exchange and a CSD in each country that due to asymmetric information, an efficient merger of the CSDs is difficult to achieve if initially the exchange and the CSD are integrated in both countries.

The paper is organized as follows: Section 2 describes the assumption of our model. Since our model is a two-stage model, we analyze the two stages in turn in the sections 3 and 4 . Section 3 looks at the behavior of investors for given prices of the exchanges and CSDs. Section 4 analyses the price setting behavior of the exchanges and CSDs under the four different industry structures described above. Finally, the welfare implications of the different industry structures are determined in section 5 .

\section{The model}

There are two countries $A$ and $B$. There is a stock exchange in each country. Furthermore, there is a CSD in both countries. All trades on the stock exchange of country $A$ are settled in the CSD of country $A$ and all trades on the stock exchange of country $B$ are settled in the CSD of country $B$. For each trade executed on exchange $A$ and then settled in CSD $A$, both the seller and the buyer have to pay $p_{A}^{T}$ to stock

\footnotetext{
${ }^{5}$ On competition among networks, see Economides (1996, 2003), Economides and Schwartz (1995).
} 
exchange $A$ and $p_{A}^{S}$ to CSD $A$. Similarly, the prices in country $B$ are $p_{B}^{T}$ and $p_{B}^{S}$. The exchanges' marginal costs for executing a trade are $c_{T}$ and the CSDs' marginal costs for settling a trade executed on an exchange are $c_{S}$.

The two CSDs maintain a bilateral (direct) link which can be used to transfer securities from one CSD to the other. For each transfer, CSD $A$ charges a price $q_{A}$ and CSD $B$ charges $q_{B}$. Each CSD incurs marginal costs of $c_{L}$ for such transfers.

In each country, there is a set $[0,1]$ of investors. Each country $A$ investor is a member of stock exchange $A$ and of CSD $A$ (i.e. has a securities account in CSD $A$ ). Similarly, each country $B$ investor is a member of stock exchange $B$ and of CSD $B$ (i.e. has a securities account in CSD $B$ ). Initially, no country $A$ investor is a member of exchange $B$ or CSD $B$ and no country $B$ investor is a member of exchange $A$ or CSD $A$. However, any investor can decide to become a (direct or indirect) member of the foreign stock exchange and CSD to be able to trade there. For simplicity, we assume that the exchanges and CSDs do not ask for a fee for this remote access. However, the (exogenous) costs for establishing remote access $-t_{T}$ for access to the respective exchange and $t_{S}$ for access to the respective CSD - are borne by the investor. These costs refer to for example IT facilities an investor needs to set up and maintain to have remote access. We define $t=t_{T}+t_{S}$ as the overall costs for remote access. ${ }^{6}$

There are two stocks. Stock $A$ has been issued into CSD $A$ and stock $B$ has been issued into CSD $B$. Both stocks are listed (and quoted) on both exchanges and thus eligible for settlement in both CSDs. Initially, each country $A$ investor owns one share of stock $A$ which is kept on his account with CSD $A$. Each country $B$ investor owns one share of stock $B$ which is kept on his account with CSD $B$. Country $A$ investors can sell stock $A$ and buy stock $B$ and country $B$ investors can sell stock $B$ and buy stock $A$. However, buying or selling abroad requires that the investor first becomes a member of the foreign exchange and CSD. Moreover, selling abroad requires that the investor first transfers his share to the foreign CSD.

An investor's benefit of holding stocks depends on the location of the investor: For $A$ investor $i \in[0,1]$, the benefit of holding one share of stock $A$ is $i$ and the benefit of holding one share of stock $B$ is $1-i$. For $B$ investor $i \in[0,1]$, the benefit of holding on share of stock $B$ is $i$ and the benefit of holding one share of stock $A$ is $1-i$. Each investor has

\footnotetext{
${ }^{6}$ If an investor is member of the foreign exchange and CSD indirectly through an intermediary, the investor would pay prices for trading and settlement abroad via its intermediary.
} 
nine alternatives given by the following table:

\begin{tabular}{|l|l|}
\hline Alternative 1 & Do not trade \\
\hline Alternative 2 & Sell home stock at home, do not trade foreign stock \\
\hline Alternative 3 & Sell home stock abroad, do not trade foreign stock \\
\hline Alternative 4 & Do not trade home stock, buy foreign stock at home \\
\hline Alternative 5 & Do not trade home stock, buy foreign stock abroad \\
\hline Alternative 6 & Sell home stock at home, buy foreign stock at home \\
\hline Alternative 7 & Sell home stock at home, buy foreign stock abroad \\
\hline Alternative 8 & Sell home stock abroad, buy foreign stock at home \\
\hline Alternative 9 & Sell home stock abroad, buy foreign stock abroad \\
\hline
\end{tabular}

Let $p_{A} \equiv p_{A}^{T}+p_{A}^{S}, p_{B} \equiv p_{B}^{T}+p_{B}^{S}$ and $q \equiv q_{A}+q_{B}$. For country $A$ investor $i \in[0,1]$, the benefits from each alternative are given by the following table:

\begin{tabular}{|l|l|}
\hline 1 & $u_{i, A}^{1}=i$ \\
\hline 2 & $u_{i, A}^{2}=r_{A A}-p_{A}$ \\
\hline 3 & $u_{i, A}^{3}=r_{A B}-t-q-p_{B}$ \\
\hline 4 & $u_{i, A}^{4}=i+1-i-r_{B A}-p_{A}$ \\
\hline 5 & $u_{i, A}^{5}=i+1-i-r_{B B}-t-p_{B}$ \\
\hline 6 & $u_{i, A}^{6}=r_{A A}+1-i-r_{B A}-2 p_{A}$ \\
\hline 7 & $u_{i, A}^{7}=r_{A A}+1-i-r_{B B}-t-p_{A}-p_{B}$ \\
\hline 8 & $u_{i, A}^{8}=r_{A B}+1-i-r_{B A}-t-q-p_{A}-p_{B}$ \\
\hline 9 & $u_{i, A}^{9}=r_{A B}+1-i-r_{B B}-t-q-2 p_{B}$ \\
\hline
\end{tabular}

Whenever we use in this paper symbols with subscripts consisting of two letters, each either $A$ or $B$ (e.g. $\left.r_{A A}, x_{B A}, S_{B B}\right)$, then the first letter refers to a stock and the second to a country. Here, $r_{A A}$ is the price of stock $A$ in country $A, r_{B A}$ is the price of stock $B$ in country $A$ and $r_{B B}$ and $r_{A B}$ denote the respective prices in country $B$. If we replace in the table the index $A$ by $B$ and the index $B$ by $A$ wherever $A$ and $B$ occur, then we get the benefits of country $B$ investor $i \in[0,1]$ for each of his nine alternatives. Note that there are economies of scope in international trading. As long as $p_{A}=p_{B}, r_{A A} \leq r_{A B}$ and $r_{B B} \leq r_{B A}$, an investor who has made the investments $t+q$ necessary to sell abroad will always buy abroad as well $\left(u_{i, A}^{9}>u_{i, A}^{8}\right)$.

Decisions are taken in two steps. First, the two exchanges and the two CSDs simultaneously set the transaction prices $p_{A}^{T}, p_{A}^{S}, p_{B}^{T}, p_{B}^{S}, q_{A}$ and $q_{B}$. Second, each investor selects one alternative out of his nine alternatives to maximize his benefit given all six transaction prices and all four stock prices. Simultaneously, the four stock prices take values such that all four stock markets are in equilibrium. 
Note that our model covers different arrangements for cross-border trading and settlement since we allow for direct remote access to the foreign exchange and CSD as well as indirect remote access through an intermediary. However, it is assumed that all trades are executed on an exchange. In other words, we assume that there is no international custodian bank that could internalize international buy and sell orders without routing them to an exchange.

\section{Stock market equilibrium}

In this section, we discuss the stock market equilibrium for given transaction prices. Determining the stock market equilibrium is quite a cumbersome exercise. Firstly, for given stock prices $r_{A A}, r_{B A}, r_{B B}$ and $r_{A B}$ and given transaction prices $p_{A}^{T}, p_{A}^{S}, p_{B}^{T}, p_{B}^{S}, q_{A}$ and $q_{B}$, the demand and supply functions for stock $A$ in country $A\left(S_{A A}\right.$ and $\left.D_{A A}\right)$, for stock $A$ in country $B\left(S_{A B}\right.$ and $\left.D_{A B}\right)$, for stock $B$ in country $A\left(S_{B A}\right.$ and $\left.D_{B A}\right)$ and for stock $B$ in country $B\left(S_{B B}\right.$ and $\left.D_{B B}\right)$ have to be determined. Details can be found in Appendix A. Secondly, for given transaction prices $p_{A}^{T}, p_{A}^{S}, p_{B}^{T}, p_{B}^{S}, q_{A}$ and $q_{B}$, the stock market equilibrium has to be found. A stock market equilibrium for given transaction prices is defined as a constellation of stock prices $r_{A A}, r_{B A}, r_{B B}$ and $r_{A B}$ such that $S_{A A}=D_{A A}=x_{A A}, S_{A B}=D_{A B}=x_{A B}, S_{B A}=D_{B A}=x_{B A}$ and $S_{B B}=D_{B B}=x_{B B}$. Here, $x_{A A}, x_{A B}, x_{B A}$ and $x_{B B}$ are the equilibrium trading volumes in the four stock markets.

However, we show in Appendix B that with this definition, there are under some parameter constellations multiple stock market equilibria with different trading volumes. For this reason, we apply the following refinement: If $p_{A} \neq p_{B}$, there may be two equilibria - one characterized by $x_{B B}=x_{A B}=0$ and another by $x_{A A}=x_{B A}=0$. In this case, we select the former if $p_{A}<p_{B}$ and the latter if $p_{A}>p_{B}$. If $p_{A}=p_{B}$, there may be infinitely many equilibria. In this case, we select the one characterized by $x_{A A}=x_{B B}$ and $x_{A B}=x_{B A}$. This refinement ensures that we have to consider exactly one equilibrium for most parameter constellations. The equilibrium is given by the following two propositions.

Proposition 1 If $t \geq q$, then the stock market equilibrium for given transaction prices is characterized by the following trading volumes:

I) If $p_{A}<p_{B}$, then

$x_{A A}=x_{B A}=\max \left\{\frac{1}{2}-\frac{1}{4}(t+q)-p_{A}, 0\right\}, x_{A B}=x_{B B}=0$.

II) If $p_{B}<p_{A}$, then

$x_{B B}=x_{A B}=\max \left\{\frac{1}{2}-\frac{1}{4}(t+q)-p_{B}, 0\right\}, x_{B A}=x_{A A}=0$.

III) If $p_{A}=p_{B}$, then

$x_{A A}=x_{B A}=x_{A B}=x_{B B}=\max \left\{\frac{1}{4}-\frac{1}{8}(t+q)-\frac{1}{2} p_{A}, 0\right\}$. 
If $t$ is relatively high and $q$ relatively low, then the link is relatively cheap and becoming a member of the exchange and the CSD of the foreign country is relatively expensive. In this case, we find that the investors are very sensitive regarding the difference between $p_{A}$ and $p_{B}$. As soon as these prices are not equal, all stocks are transferred via the link from the country with the higher to the country with the lower trading and settlement price and all trade takes place in the country with the lower price. I.e. trading and settlement in country $A$ and trading and settlement in country $B$ are perfect substitutes.

Note that if $p_{A}=p_{B}$, all linear combinations of the trading volumes under I) and II) would characterize an equilibrium if we did not use the above refinement. Since we have $x_{A A}=x_{B A}=x_{A B}=x_{B B}$ for $p_{A}=p_{B}$, half of the trading country $A$ investors sell in country $B$ and half of the trading country $B$ investors sell in country $A$. These are the investors who use the link. Furthermore, it follows that these and only these investors buy abroad. I.e. every trading investor either uses the link by himself or trades with an investor who uses the link. And those investors who do not use the link do not become members of the foreign exchange and the foreign CSD. In other words, for given trading volumes, remote membership is created as little as possible and the link is used as much as possible. In equilibrium, we find that $r_{A B}=r_{B A}>r_{A A}=r_{B B}$, i.e. the investors who use the link are compensated by favorable stock prices for the additional transaction costs they bear. This also implies that the investors exploit the economies of scope mentioned in the previous section: No investor will ever sell abroad and buy at home.

The situation looks very different in case that $t \leq q$ :

Proposition 2 If $t \leq q$, then the stock market equilibrium for given transaction prices is characterized by the following trading volumes:

I) If $\left|p_{A}-p_{B}\right| \leq \frac{1}{2}(q-t)$, then

$x_{A A}=\max \left\{\frac{1-t}{2}-p_{A}, 0\right\}, x_{B B}=\max \left\{\frac{1-t}{2}-p_{B}, 0\right\}, x_{B A}=x_{A B}=0$.

II) If $p_{B}-p_{A} \geq \frac{1}{2}(q-t)$, then

$x_{A A}=\max \left\{\frac{1-t}{2}-p_{A}, 0\right\}, x_{B A}=\max \left\{\frac{1-q}{2}-p_{A}, 0\right\}, x_{A B}=x_{B B}=0$.

III) If $p_{A}-p_{B} \geq \frac{1}{2}(q-t)$, then

$x_{B B}=\max \left\{\frac{1-t}{2}-p_{B}, 0\right\}, x_{A B}=\max \left\{\frac{1-q}{2}-p_{B}, 0\right\}, x_{B A}=x_{A A}=0$.

If $t$ is relatively low and $q$ relatively high, the link is relatively expensive and becoming a member of the foreign exchange and CSD is relatively cheap. In this case, we find that $x_{A A}$ and $x_{B B}$ are positive and $x_{A B}=x_{B A}=0$, if the difference between $p_{A}$ and $p_{B}$ is moderate. I.e. investors from both countries become members of the respective foreign exchange and CSD and the link is not used. Stock $A$ is traded only in 
country $A$ and stock $B$ is traded only in country $B$. Only if the difference between $p_{A}$ and $p_{B}$ is sufficiently high, all stocks are transferred via the link from the country with the higher to the country with the lower trading and settlement price and all trade takes place in the country with the lower price. I.e. trading and settlement in country A and trading and settlement in country B are now imperfect substitutes. ${ }^{7}$

\section{Transaction price equilibrium}

After determining the stock market trading volumes in equilibrium for given transaction prices, we now look at the first stage of the model. Here, the transactions prices are set by the two exchanges and the two CSDs.

\subsection{Payoff functions}

To begin with, we define the payoff functions of the players. The profit function of exchange $A$ is defined by

$$
\pi_{A}^{T}=2\left(x_{A A}+x_{B A}\right)\left(p_{A}^{T}-\frac{1}{2} c_{T}\right)
$$

and for exchange $B$, we get

$$
\pi_{B}^{T}=2\left(x_{B B}+x_{A B}\right)\left(p_{B}^{T}-\frac{1}{2} c_{T}\right)
$$

Note that an exchange receives the price $p_{A}^{T}$ or $p_{B}^{T}$ twice for each trade executed because both the seller and the buyer have to pay the price. This is way the trading quantities are multiplied by 2 . However, $c_{T}$ is defined as the costs of the exchange for executing a trade.

For the CSDs, we get

$$
\pi_{A}^{S}=2\left(x_{A A}+x_{B A}\right)\left(p_{A}^{S}-\frac{1}{2} c_{S}\right)+\left(x_{A B}+x_{B A}\right)\left(q_{A}-c_{L}\right)
$$

and

$$
\pi_{B}^{S}=2\left(x_{B B}+x_{A B}\right)\left(p_{B}^{S}-\frac{1}{2} c_{S}\right)+\left(x_{A B}+x_{B A}\right)\left(q_{B}-c_{L}\right)
$$

The first term refers to the profits from settling trades on the respective exchange, while the second term refers to profits from operating the link.

\footnotetext{
${ }^{7}$ Note that 2 describes two equilibria for $\left|p_{A}-p_{B}\right|=\frac{1}{2}(q-t)$. In fact, all linear combinations of these two equilibria are also equilibria in this case. We have omitted a detailed description of this case, because it has no impact on the further analysis. Furthermore, note that for $t=q$, the two propositions describe two different equilibria.
} 
Since we are going to look at different industry structures, we define $\pi_{A}=\pi_{A}^{T}+\pi_{A}^{S}$ and $\pi_{B}=\pi_{B}^{T}+\pi_{B}^{S}$ as the profit of a company operating both the exchange and the CSD in the respective country (vertical integration of exchange and CSD). The profit of a company operating both CSDs would be $\pi_{S}=\pi_{A}^{S}+\pi_{B}^{S}$ (horizontal integration in settlement).

In the following three sections, we analyze the equilibrium transaction prices and trading volumes under different industry structures. However, before we enter into the analysis, a few things should be noted.

First, for any given parameter constellation, there is a multiplicity of no-trade equilibria which we will ignore. Assume that both exchanges set prices that are so high that the demand for trade would be zero even if both settlement (and link) prices are zero. It is clear that any settlement prices are best responses of the operators of the CSDs. Analogously, assume that both CSDs set settlement prices that are so high that the demand for trade would be zero even if both trading prices are zero. Now any trading prices are best responses of the exchanges. Thus, there are always equilibria with no trade and prohibitively high prices for trading and settlement. Since such equilibria describe extreme coordination failures and characterize hardly interesting trading allocations, we ignore them.

Second, under certain circumstances there are equilibria in which the marginal costs for trading and/or for the settlement of trades are higher than the respective prices (i.e. $p_{A}^{S}<\frac{1}{2} c_{S}$ and/or $p_{B}^{S}<\frac{1}{2} c_{S}$ and $p_{A}^{T}<\frac{1}{2} c_{T}$ and/or $\left.p_{B}^{T}<\frac{1}{2} c_{T}\right){ }^{8}$ We ignore these equilibria, too.

Finally, to avoid corner solutions in equilibrium, we assume $\alpha \geq 0$ and $\beta \geq 0$ with

$$
\begin{aligned}
\alpha & \equiv 1-t-c_{S}-c_{T} \\
\beta & \equiv 1-\frac{1}{2} t-c_{S}-c_{T}-c_{L}
\end{aligned}
$$

\subsection{Complete separation}

To begin with, we look at an industry in which all four service providers are operated independently by different companies. We concentrate on symmetric equilibria only, i.e. equilibria with $p_{A}^{S}=p_{B}^{S}, p_{A}^{T}=p_{B}^{T}$ and $q_{A}=q_{B}$. The following proposition describes an equilibrium in which the link is used.

Proposition 3 If $t-2 c_{L}>2 \alpha$, then there is one and only one symmetric equilibrium in which the link is used.

\footnotetext{
${ }^{8}$ This is possible because companies that offer more than one service, for example settlement and link services or - in case of vertical integration - trading and settlement services, can cross-subsidize the different services.
} 
(1) If $t-2 c_{L}>4 \alpha$, it is characterized by

$$
\begin{aligned}
p_{A}^{T} & =p_{B}^{T}=\frac{1}{2} c_{T}, p_{A}^{S}=p_{B}^{S}=\frac{1}{2} c_{S}, q_{A}=q_{B}=\frac{2}{3} \beta+c_{L} \\
x_{A A} & =x_{B A}=x_{A B}=x_{B B}=\frac{1}{12} \beta
\end{aligned}
$$

(2) If $4 \alpha>t-2 c_{L}>2 \alpha$, then it is characterized by

$$
\begin{aligned}
p_{A}^{T} & =p_{B}^{T}=\frac{1}{2} c_{T}, p_{A}^{S}=p_{B}^{S}=\frac{1}{2} c_{S}, q_{A}=q_{B}=\frac{1}{2} t \\
x_{A A} & =x_{B A}=x_{A B}=x_{B B}=\frac{1}{4} \alpha
\end{aligned}
$$

If $t-2 c_{L}<2 \alpha$, then there is no symmetric equilibrium in which the link is used.

First note that only if the operating $\operatorname{costs} c_{L}$ of the link are sufficiently low, there is an equilibrium in which the link is used. Note also that in this equilibria, both the trading and the settlement prices are equal to marginal costs. The reason is that if $c_{L}$ is low, so then are the prices $q_{A}$ and $q_{B}$ for the link and it is cheap to substitute trading and settlement in one country for trading and settlement in the other country. The exchange and the CSD in country $A$ enter into perfect price competition with the exchange and CSD in country $B$. This leads to a situation in which the prices equal marginal costs. Note that part (2) of the proposition describes corner cases with $q_{A}=q_{B}=\frac{1}{2} t$.

According to proposition 3, an equilibrium in which the link is used exists only if $t-2 c_{L}>2 \alpha$. However, there is always an equilibrium in which the link is not used:

Proposition 4 There are always symmetric equilibria in which the link is not used. The set of all such equilibria is characterized by

$$
\begin{aligned}
p_{A}^{T} & =p_{B}^{T}=\frac{1}{6}\left(1-t-c_{S}+2 c_{T}\right), p_{A}^{S}=p_{B}^{S}=\frac{1}{6}\left(1-t-c_{T}+2 c_{S}\right), \\
q_{A} & =q_{B} \geq \frac{1}{2} t \\
x_{A A} & =x_{B B}=\frac{1}{6} \alpha, x_{B A}=x_{A B}=0
\end{aligned}
$$

One might not be surprised to find an equilibrium in which the link is not used, if $c_{L}$ is high. It is also not a surprise that in such an equilibrium, trading and settlement prices are higher than marginal costs since there is no (direct) competition between the two countries if $c_{L}$ and thus the 
link prices are high. However, why are there equilibria in which the link is not used, if $c_{L}$ is low? The reason is a simple coordination problem: If for example $q_{A}$ is, say, higher than $t$, then the link will not be used no matter how low $q_{B}$ is. CSD $B$ has therefore no reason not to set $q_{B}>t$. For the same reasons, CSD $A$ has now no reason not to set $q_{A}>t$. Thus, $q_{A}=q_{B} \geq t$ always constitutes an equilibrium.

Thus, we do not have a unique equilibrium, if $t-2 c_{L}>2 \alpha$. However, there are good reasons to select in this case the equilibrium described in proposition 3. Firstly, it is easy to show that the CSDs reach a higher profit in the equilibrium described in proposition 3 than in the one of proposition 4. Secondly, we have argued in the previous subsection that we do not consider equilibria in which there is no trade at all due to coordination failures. For the same reasons, we can ignore the equilibria of proposition 4 in case that $t-2 c_{L}>2 \alpha$. I.e. from now on, we assume that the CSDs coordinate on the equilibrium described in proposition 3 whenever $t-2 c_{L}>2 \alpha$.

\subsection{Vertical Integration}

We now assume that in both countries the CSD and the exchange are operated by the same firm. The operator of the silo in country $A$ sets $p_{A}^{S}$, $p_{A}^{T}$ and $q_{A}$, the operator of the other silo simultaneously sets $p_{B}^{S}, p_{B}^{T}$ and $q_{B}$. Again, we concentrate on symmetric equilibria only, i.e. equilibria with $p_{A}^{S}=p_{B}^{S}, p_{A}^{T}=p_{B}^{T}$ and $q_{A}=q_{B}$ and find:

Proposition 5 Proposition 3 holds also under vertical integration.

The economic intuition for this result is of course the same as for proposition 3. If $c_{L}$ is low, it is cheap to transfer securities from one country to the other. The operator of the exchange and the CSD in country $A$ and the operator of those in country $B$ enter into perfect competition so that trading and settlement fees go down to marginal costs.

As under complete separation, there is always an equilibrium in which the link is not used:

Proposition 6 There are always symmetric equilibria in which the link is not used. The set of all such equilibria is characterized by

$$
\begin{aligned}
p_{A}^{T}+p_{A}^{S} & =p_{B}^{T}+p_{B}^{S}=\frac{1}{4}\left(1-t+c_{S}+c_{T}\right), \\
q_{A} & =q_{B} \geq \frac{1}{2} t \\
x_{A A} & =x_{B B}=\frac{1}{4} \alpha, x_{B A}=x_{A B}=0
\end{aligned}
$$


Note that the trading and settlement prices are lower in the equilibrium of proposition 6 than in the one of proposition 4 . The reason is that the CSD and the exchange of a given country offer complements. As explained in the introduction, mergers of firms that offer complements reduce prices.

Again, we do not have a unique equilibrium if $t-2 c_{L}>2 \alpha$. But it is again easy to see that the CSD's profits are higher in the equilibrium described in proposition 5 than in the one of proposition 6 . For that reason and because proposition 6 describes equilibria that are due to coordination failures if $c_{L}$ is low, we assume again that the CSDs coordinate on the equilibrium described in proposition 5 whenever $t-2 c_{L}>2 \alpha$.

\subsection{Horizontal integration of CSDs}

We now look at a horizontally integrated structure, i.e. the two CSDs are operated by one company. In this case, we have three players. The operator of exchange $A$ sets $p_{A}^{T}$ and has payoff function $\pi_{A}^{T}$. The operator of exchange $B$ sets $p_{B}^{T}$ and has payoff function $\pi_{B}^{T}$. Finally, the operator of the two CSDs sets $p_{A}^{S}, p_{B}^{S}, q_{A}$ and $q_{B}$; his payoff function is $\pi_{S}$. We assume that the operator of the CSDs cannot price-discriminate between the two countries, i.e. he has to set $p_{A}^{S}=p_{B}^{S}$. This assumption can be justified by the existence of competition authorities like the European Commission in the EU that would not allow price discrimination. We first consider a purely legal integration of the CSDs. Concentrating only on symmetric equilibria $\left(p_{A}^{T}=p_{B}^{T}\right)$, we get

Proposition 7 (1) For $t-2 c_{L}>0$, the set of all symmetric equilibria is characterized by

$$
\begin{aligned}
& p_{A}^{T}=p_{B}^{T}=\frac{1}{2} c_{T}, q+4 p_{A}^{S}=1-\frac{1}{2} t+c_{S}+c_{L}-c_{T}, p_{A}^{S}=p_{B}^{S}, q \leq t \\
& x_{A A}=x_{B A}=x_{A B}=x_{B B}=\frac{1}{8} \beta
\end{aligned}
$$

(2) For $t-2 c_{L}<0$, the set of all symmetric equilibria is characterized by

$$
\begin{aligned}
p_{A}^{T} & =p_{B}^{T}=\frac{1}{6}\left[1-t+2 c_{T}-c_{S}\right], p_{A}^{S}=p_{B}^{S}=\frac{1}{6}\left[1-t+2 c_{S}-c_{T}\right], \\
q & \geq t \\
x_{A A} & =x_{B B}=\frac{1}{6} \alpha, x_{B A}=x_{A B}=0
\end{aligned}
$$

If $c_{L}$ is low, i.e. $t-2 c_{L}>0$, then $q$ is low and the two exchanges enter into perfect price competition that leads to a situation in which 
the trading prices are equal to marginal costs. However, the prices for settlement and for the link are not unique, but only the weighted sum $q+4 p_{A}^{S}$ of both. The reason is subtle, but important to note. Remember that there are economies of scope in our model: if an investor decides to sell abroad, he will buy abroad as well. If he is for example a country $B$ investor, then the transaction price he has to pay to the integrated CSDs is $q+2 p_{A}^{S}$, the country $A$ investor he sells to pays $p_{A}^{S}$ and the country $A$ investor he buys from also pays $p_{A}^{S}$. The total transaction price paid by investors to the CSDs is thus $q+4 p_{A}^{S}$. If now $q$ increases and $4 p_{A}^{S}$ decreases by the same amount so that $q+4 p_{A}^{S}$ remains unchanged, then the $B$ investor pays more and the two investors from country $A$ pay less. However, it can be shown that now, $r_{A B}$ increases and $r_{B B}$ decreases until the $B$ investor is compensated for that. Thus, if $q$ increases and $q+4 p_{A}^{S}$ remains unchanged, the investors' equilibrium behavior does not change.

We still look at $t-2 c_{L}>0$ and compare the prices for settlement and for the link given by the propositions 7, 3 and 5. The settlement services of the two CSDs are substitutes, while their link services are complements. For that reason, one would expect that $p_{A}^{S}$ and $p_{B}^{S}$ are higher under horizontal integration, while $q$ is higher under complete separation and under vertical integration. However, since the prices for settlement and for the link are not unique under horizontal integration, we can only compare the weighted sum $q+4 p_{A}^{S}$. It is easy to show that $q+4 p_{A}^{S}$ is higher under complete separation and under vertical integration than it is under horizontal integration. The reason is closely related to what was explained in the previous paragraph. Investors' choice only depends on the weighted sum $q+4 p_{A}^{S}$. That reveals a relation between the two settlement services on the one hand and the two link services on the other: they are perfect complements. Using the link is beneficial for investors only if they afterwards use the settlement service of one CSD. And the settlement service of a CSD is used only if the link services are used before. This is due to the economies of scope described above. As the settlement services and the link services are complements, prices are lower if all these services are provided by the same player, i.e. under horizontal integration.

Finally, if $t-2 c_{L}<0$, then the link is too expensive to be used and purely legal horizontal integration and complete separation lead to the same results.

Now consider a complete technical integration of the CSDs. I.e. the two CSDs are operated on the same system and the operating costs of the link are thus $c_{L}=0$, while $t_{S}=0$ as well. The equilibrium for this case now follows directly from part (1) of proposition 7: 
Proposition 8 For $c_{L}=t_{S}=0$ (THI), the set of all symmetric equilibria is characterized by

$$
\begin{gathered}
p_{A}^{T}=p_{B}^{T}=\frac{1}{2} c_{T}, q+4 p_{A}^{S}=1-\frac{1}{2} t_{T}+c_{S}-c_{T}, p_{A}^{S}=p_{B}^{S} \\
x_{A A}=x_{B A}=x_{A B}=x_{B B}=\frac{1}{8}\left[1-\frac{1}{2} t_{T}-c_{S}-c_{T}\right]
\end{gathered}
$$

It should be mentioned here that a THI may entail substantial costs that are to be borne by the operator of the integrated CSDs. Since we ignore in our model these costs, proposition 8 describes a longer-term equilibrium while in the short run, the operator of the CSD may add a surcharge to its prices to cover the cost of THI.

\section{$5 \quad$ Welfare analysis}

We now compare the welfare characteristics of the different industry structures discussed above. We first determine the general net social benefit function and describe the general welfare maximum. We than calculate the net social benefits for the different industry structures.

\subsection{Net social benefit function and welfare maxi- mum}

We start with the net benefits from trade of the country A investors and of the country B investors. Country A investors sell a volume of $x_{A A}+$ $x_{A B}$ of stock A to country B investors and buy a volume of $x_{B B}+x_{B A}$ of stock B from country B investors. Those country A investors who do not sell have a benefit of holding stock A of

$$
\int_{x_{A A}+x_{A B}}^{1} i d i
$$

Those country A investors who sell stock A have a benefit of selling it of

$$
x_{A A}\left(r_{A A}-p_{A}\right)+x_{A B}\left(r_{A B}-p_{B}-q\right)
$$

Those country A investors who buy stock B have a benefit of doing this of

$$
\int_{0}^{x_{B B}+x_{B A}}(1-i) d i-x_{B B}\left(r_{B B}+p_{B}\right)-x_{B A}\left(r_{B A}+p_{A}\right)
$$

On top of that, country A investors who trade in country B must get connected to country B. Note the following: Each investor who want to 
trade in country B needs to get connected to country B only once, even if he trades both stocks in country B. Furthermore, a situation in which some country A investors trade in country B only stock A and some other country A investors trade in country B only stock B is not possible. I.e. the overall number of country A investors who get connected to country $\mathrm{B}$ is $\max \left\{x_{B B}, x_{A B}\right\}$ and the costs for country $\mathrm{A}$ investors from getting connected to country $\mathrm{B}$ are thus given by $t \max \left\{x_{B B}, x_{A B}\right\}$. The net benefit of country $A$ investors is given by the sum of these three first components minus $t \max \left\{x_{B B}, x_{A B}\right\}$, i.e. by

$$
\begin{aligned}
B_{A}= & \frac{1}{2}-\frac{1}{2}\left(x_{A A}+x_{A B}\right)^{2}-\frac{1}{2}\left(x_{B B}+x_{B A}\right)^{2}+\left(x_{B B}+x_{B A}\right) \\
& -t \max \left\{x_{B B}, x_{A B}\right\}+x_{A A}\left(r_{A A}-p_{A}\right)+x_{A B}\left(r_{A B}-p_{B}-q\right) \\
& -x_{B A}\left(r_{B A}+p_{A}\right)-x_{B B}\left(r_{B B}+p_{B}\right)
\end{aligned}
$$

We get the net benefits $B_{A}$ of country $\mathrm{B}$ investors in a similar way. The net benefits of the economy as a whole is given by

$$
\begin{aligned}
B= & B_{A}+B_{B}+\pi_{A}^{T}+\pi_{B}^{T}+\pi_{A}^{S}+\pi_{B}^{S} \\
= & \left(1-c_{S}-c_{T}\right)\left[x_{A A}+x_{A B}+x_{B B}+x_{B A}\right]-\left(x_{A A}+x_{A B}\right)^{2}-\left(x_{B B}+x_{B A}\right)^{2} \\
& -2 c_{L}\left(x_{A B}+x_{B A}\right)-t \max \left\{x_{B B}, x_{A B}\right\}-t \max \left\{x_{A A}, x_{B A}\right\}+1
\end{aligned}
$$

It is now easy to determine the welfare maximum, i.e. the maximiser of the function $B$. It is given by

Proposition 9 If $2 c_{L}<t$, then the welfare maximum is obtained with $x_{A A}=x_{B B}=x_{A B}=x_{B A}=\frac{1}{4} \beta$. If $2 c_{L}>t$, then it is obtained with $x_{A A}=x_{B B}=\frac{1}{2} \alpha, x_{A B}=x_{B A}=0$.

Note that it is optimal to have trading of both securities in both countries and thus to use the link if the operating costs of the link are relatively low $\left(2 c_{L}<t\right)$. Given the relations described in the propositions 1 and 2 , these welfare maximising trading volumes can be implemented with the prices $p_{A}=p_{B}=\frac{1}{2} c_{T}+\frac{1}{2} c_{S}$ and $q=2 c_{L}$ (prices equal to marginal costs).

\subsection{Comparison of social benefits for different in- dustry structures}

Taking now the results from the previous section, it is easy to calculate the net social benefits for the different industry structures. For CS, it is given by

$$
B_{C S}\left(c_{L}\right)=\left\{\begin{array}{l}
1+\frac{5}{18} \beta^{2}, \text { if } t-2 c_{L}>4 \alpha \\
1+\alpha \beta-\frac{1}{2} \alpha^{2}, \text { if } 4 \alpha>t-2 c_{L}>2 \alpha \\
1+\frac{5}{18} \alpha^{2}, \text { if } 2 \alpha>t-2 c_{L}
\end{array}\right.
$$


In a similar way, we find for VI

$$
B_{V I}\left(c_{L}\right)=\left\{\begin{array}{l}
1+\frac{5}{18} \beta^{2}, \text { if } t-2 c_{L}>4 \alpha \\
1+\alpha \beta-\frac{1}{2} \alpha^{2}, \text { if } 4 \alpha>t-2 c_{L}>2 \alpha \\
1+\frac{3}{8} \alpha^{2}, \text { if } 2 \alpha>t-2 c_{L}
\end{array}\right.
$$

For LHI, we get

$$
B_{L H I}\left(c_{L}, t\right)=\left\{\begin{array}{l}
1+\frac{3}{8} \beta^{2}, \text { if } t-2 c_{L}>0 \\
1+\frac{5}{18} \alpha^{2}, \text { if } 0>t-2 c_{L}
\end{array}\right.
$$

Finally, we have

$$
B_{T H I}=B_{L H I}\left(0, t=t_{T}\right)=1+\frac{3}{8}\left[1-\frac{1}{2} t_{T}-c_{S}-c_{T}\right]^{2}
$$

The comparison of the net social benefits is straightforward and given by

Theorem 10 If $t>2 c_{L}$, then $B_{T H I}>B_{L H I}>B_{V I}=B_{C S}$. If $2 c_{L}>t$, then $B_{T H I}>B_{V I}>B_{L H I}=B_{C S}$.

To understand this result, we only have to compare equilibrium prices since it is clear that the lower the equilibrium prices the higher the social benefits. The intuition for the differences in equilibrium prices for the different industry structures has been discussed already in section 4 . If $t>2 c_{L}$, then there is a strong complementary relation between the services provided by the two CSDs. The two link services are complements. And the link service of one and the settlement service of the other CSD are complements. The prices are therefore lower if all these services are offered by the same player and $B_{L H I}>B_{V I}=B_{C S}$. If $t<2 c_{L}$, then the link is too expensive to be used. What matters are the settlement services of the CSDs and these are neither substitutes not complements if $t<2 c_{L}$. Since trading and settlement within a country are complements, the prices for these services are lower if they are offered by the same player so that we get $B_{V I}>B_{L H I}=B_{C S}$. Finally, if $2 c_{L}>t$, then the cost saving effect of THI is so high that $B_{T H I}>B_{V I} \cdot{ }^{9}$

\footnotetext{
${ }^{9}$ Assume that LHI already leads to a cost saving effect so that it reduces the link operating costs to $\bar{c}_{L}<c_{L}$. If $2 \bar{c}_{L} \leq t$, then LHI would now outperform VI even if $t<2 c_{L}$. Thus, horizontal integration is already the best type of consolidation if it makes the economic cost of the link smaller than the cost of remote access.
} 


\section{Concluding remarks}

In this paper, we have analyzed the welfare implications of different structures of the securities trading and settlement industry in a twocountry model. The result of our analysis is remarkably simple: Complete horizontal integration of CSDs leads to a higher welfare than vertical integration of exchanges and CSDs and vertical integration leads to a higher welfare than complete separation.

However, it should be emphasized that this paper is only a first step to analyze a complex question. More research is needed to get the complete picture and final policy conclusions should not yet be drawn. In this context, two limitations of the model mentioned already in the introduction need to be emphasized again: Firstly, we assume that the CSDs cannot compete for the exchanges, i.e. each exchange is forced to settle all trades in the domestic CSD. And secondly, we do not allow for OTC trading (including internalization of trades by an international custodian bank), i.e. all trades are executed on an exchange. Both assumptions might have influenced our results. It is left to future research to look at the welfare implications of horizontal and vertical integration in securities trading and settlement from other angles.

Another critical aspect of our model is the assumption that due to the preferences of investors, all trades are cross-border trades, i.e. with the buyer and seller located in different countries. However, it is now easy to predict what kind of results one would get under alternative assumptions. The opposite extreme would be to assume that all trades are domestic trades, i.e. between investors located in the same country. Country $A$ investors would have demand only for $A$ securities and $B$ investors only for $B$ securities. In this case, the link would never be used. Note that there would now be no competitive relation between service providers in different countries. Accordingly, horizontal integration of CSDs and complete separation would lead to exactly the same results. However, vertical integration would lead to a higher welfare than separation and horizontal integration since the only thing that matters is the fact that in each country, the exchange and the CSD offer complements. From these consideration, a simple lesson can be learned. If domestic investors have little interest in holding foreign securities, vertical integration of domestic service providers may be desirable. If investors have instead strong preferences for foreign securities, horizontal integration of CSDs may be the best from a welfare perspective.

Finally, it should be emphasized that we did not look at horizontal integration of exchanges. If we had done that in our model, we would probably have come to the conclusion that exchanges should not merge since they offer substitutes. However, there may still be good reasons 
why exchanges should merge which are not taken into account in our model. For example, mergers of exchanges lead to a concentration of liquidity. This liquidity concentration effect however does not occur in our model.

\section{Appendix A}

In this appendix, the demand and supply functions of the investors for given transaction prices and stock prices are determined. Each investor selects the alternative that gives him the highest benefit according to the tables in section 2. Note that in the benefits for the alternatives 2 to 5 , the name $i$ of the respective investor does not occur, i.e. all investors located in the same country have the same preferences over these four alternatives. Similarly, all investors located in the same country have the same preferences over the alternatives 6 to 9 . To begin with, we look at the country $A$ investors and have to consider several cases:

(1) $u_{i, A}^{6} \geq \max \left\{u_{i, A}^{7}, u_{i, A}^{8}, u_{i, A}^{9}\right\}$. First note that $u_{i, A}^{6} \geq \max \left\{u_{i, A}^{7}, u_{i, A}^{8}\right\} \Rightarrow$ $u_{i, A}^{6} \geq u_{i, A}^{9}$ so that the latter is redundant. Moreover, we easily find that $u_{i, A}^{6} \geq u_{i, A}^{7} \Leftrightarrow u_{i, A}^{4}>u_{i, A}^{5}$ and $u_{i, A}^{6}>u_{i, A}^{8} \Leftrightarrow u_{i, A}^{2}>u_{i, A}^{3}$. I.e. we have to distinguish two subcases:

(1a) $u_{i, A}^{2} \geq u_{i, A}^{4}$. In this case, each investor selects either alternative 1 or alternative 2 or alternative 6 , i.e. we have to compare $u_{i, A}^{1}, u_{i, A}^{2}$ and $u_{i, A}^{6}$ :

$$
\begin{aligned}
& u_{i, A}^{1} \geq u_{i, A}^{2} \Leftrightarrow i \geq r_{A A}-p_{A} \equiv \alpha_{1} \\
& u_{i, A}^{1} \geq u_{i, A}^{6} \Leftrightarrow i \geq \frac{r_{A A}+1-r_{B A}}{2}-p_{A} \equiv \alpha_{2} \\
& u_{i, A}^{2} \geq u_{i, A}^{6} \Leftrightarrow i \geq 1-r_{B A}-p_{A} \equiv \alpha_{3}
\end{aligned}
$$

Note that $u_{i, A}^{2} \geq u_{i, A}^{4} \Leftrightarrow r_{A A} \geq 1-r_{B A}$. It follows that $\alpha_{1} \geq \alpha_{2} \geq \alpha_{3}$. I.e. all investors $i \in\left[0, \alpha_{3}\right]$ choose alternative 6 , all investors $i \in\left[\alpha_{3}, \alpha_{1}\right]$ choose alternative 2 and all investors $i \in\left[\alpha_{1}, 1\right]$ choose alternative 1 . From this, we get the supply and demand functions as follows:

$$
\begin{aligned}
S_{A A} & =\left\{\begin{array}{c}
0, \text { if } \alpha_{1}<0 \\
\alpha_{1}, \text { if } 0 \leq \alpha_{1} \leq 1 \quad D_{B A}=\left\{\begin{array}{c}
0, \text { if } \alpha_{3}<0 \\
1, \text { if } \alpha_{1}>1
\end{array}\right. \\
\alpha_{3}, \text { if } 0 \leq \alpha_{3} \leq 1 \\
1, \text { if } \alpha_{3}>1
\end{array}\right. \\
S_{A B} & =0, D_{B B}=0
\end{aligned}
$$

Here, $S_{A A}$ is the supply of stock $A$ in country $A, S_{A B}$ is the supply of stock $A$ in country $B$ and $D_{B A}$ and $D_{B B}$ denote the respective demand for stock $B$.

(1b) $u_{i, A}^{4} \geq u_{i, A}^{2}$. In this case, each investor selects either alternative 1 or alternative 4 or alternative 6 , i.e. we have to compare $u_{i, A}^{1}, u_{i, A}^{4}$ and 
$u_{i, A}^{6}$ :

$$
\begin{aligned}
& u_{i, A}^{1} \geq u_{i, A}^{4} \Leftrightarrow i \geq 1-r_{B A}-p_{A} \equiv \alpha_{3} \\
& u_{i, A}^{1} \geq u_{i, A}^{6} \Leftrightarrow i \geq \frac{r_{A A}+1-r_{B A}}{2}-p_{A} \equiv \alpha_{2} \\
& u_{i, A}^{4} \geq u_{i, A}^{6} \Leftrightarrow i \geq r_{A A}-p_{A} \equiv \alpha_{1}
\end{aligned}
$$

Note that $u_{i, A}^{4} \geq u_{i, A}^{2} \Leftrightarrow 1-r_{B A} \geq r_{A A}$. It follows that $\alpha_{3} \geq \alpha_{2} \geq \alpha_{1}$. I.e. all investors $i \in\left[0, \alpha_{1}\right]$ choose alternative 6 , all investors $i \in\left[\alpha_{1}, \alpha_{3}\right]$ choose alternative 4 and all investors $i \in\left[\alpha_{3}, 1\right]$ choose alternative 1 . From that, we get exactly the same supply and demand functions as in case (1a). Thus, we get

$$
\text { If } \begin{aligned}
u_{i, A}^{6}>\max \left\{u_{i, A}^{7}, u_{i, A}^{8}\right\}, \text { then } \\
\qquad \begin{aligned}
& 0, \text { if } \alpha_{1}<0 \\
& S_{A A}=\left\{\begin{array}{c}
\alpha_{1}, \text { if } 0 \leq \alpha_{1} \leq 1 \\
1, \text { if } \alpha_{1}>1
\end{array} \quad, D_{B A}=\left\{\begin{array}{c}
0, \text { if } \alpha_{3}<0 \\
\alpha_{3}, \text { if } 0 \leq \alpha_{3} \leq 1 \\
1, \text { if } \alpha_{3}>1
\end{array}\right.\right.
\end{aligned} \\
S_{A B}=0, D_{B B}=0
\end{aligned}
$$

As one would expect, $S_{A A}$ is increasing in $r_{A A}, D_{B A}$ is decreasing in $r_{B A}$ and both functions are decreasing in $p_{A}$. Note that we do not necessarily have $\alpha_{1}=\alpha_{3}$. It is immediate that $\alpha_{1}>\alpha_{3} \Leftrightarrow u_{i, A}^{2} \geq u_{i, A}^{4}$. Here, country $A$ investors $i \in\left[0, \alpha_{3}\right]$ choose alternative 6 , i.e. sell stock $A$ and buy stock $B$ in country $A$. $A$ investors $i \in\left[\alpha_{3}, \alpha_{1}\right]$ choose alternative 2, i.e. sell stock $A$ in country $A$ and do not trade stock $B$. Finally, $A$ investors $i \in\left[\alpha_{1}, 1\right]$ choose alternative 1, i.e. do not trade at all. If instead $\alpha_{3}>\alpha_{1}$, we find $u_{i, A}^{4} \geq u_{i, A}^{2}$. In this case, all investors $i \in\left[0, \alpha_{1}\right]$ choose alternative 6 , all investors $i \in\left[\alpha_{1}, \alpha_{3}\right]$ choose alternative 4 and all investors $i \in\left[\alpha_{3}, 1\right]$ choose alternative 1 .

For the next two cases, we get the supply and demand in a very similar way:

(2) $u_{i, A}^{7}>\max \left\{u_{i, A}^{6}, u_{i, A}^{8}, u_{i, A}^{9}\right\}$. We find that $u_{i, A}^{7}>\max \left\{u_{i, A}^{6}, u_{i, A}^{9}\right\} \Rightarrow$ $u_{i, A}^{7}>u_{i, A}^{8}$ so that the latter condition is redundant and get

$$
\text { If } \begin{aligned}
u_{i, A}^{7} & >\max \left\{u_{i, A}^{6}, u_{i, A}^{9}\right\} \text { then } \\
S_{A A} & =\left\{\begin{array}{c}
0, \text { if } \alpha_{1}<0 \\
\alpha_{1}, \text { if } 0 \leq \alpha_{1} \leq 1, \\
1, \text { if } \alpha_{1}>1
\end{array}, D_{B B}=\left\{\begin{array}{c}
0, \text { if } \alpha_{5}<0 \\
\alpha_{5}, \text { if } 0 \leq \alpha_{5} \leq 1 \\
1, \text { if } \alpha_{5}>1
\end{array}\right.\right. \\
D_{B A} & =0, \quad S_{A B}=0
\end{aligned}
$$

with $\alpha_{5} \equiv 1-r_{B B}-t-\left(p_{B}^{T}+p_{B}^{S}\right)$. 
(3) $u_{i, A}^{8}>\max \left\{u_{i, A}^{6}, u_{i, A}^{7}, u_{i, A}^{9}\right\}$. Here, we find $u_{i, A}^{8}>\max \left\{u_{i, A}^{6}, u_{i, A}^{9}\right\} \Rightarrow$ $u_{i, A}^{8}>u_{i, A}^{7}$ and

If $u_{i, A}^{8}>\max \left\{u_{i, A}^{6}, u_{i, A}^{9}\right\}$ then

$$
\begin{aligned}
& S_{A B}=\left\{\begin{array}{c}
0, \text { if } \alpha_{6}<0 \\
\alpha_{6}, \text { if } 0 \leq \alpha_{6} \leq 1 \\
1, \text { if } \alpha_{6}>1
\end{array}, \quad D_{B A}=\left\{\begin{array}{c}
0, \text { if } \alpha_{3}<0 \\
\alpha_{3}, \text { if } 0 \leq \alpha_{3} \leq 1 \\
1, \text { if } \alpha_{3}>1
\end{array}\right.\right. \\
& S_{A A}=0, D_{B B}=0
\end{aligned}
$$

with $\alpha_{6} \equiv r_{A B}-t-\left(q_{A}+q_{B}\right)-\left(p_{B}^{T}+p_{B}^{S}\right)$.

For the last case, matters are somewhat more complicated:

(4) $u_{i, A}^{9}>\max \left\{u_{i, A}^{6}, u_{i, A}^{7}, u_{i, A}^{8}\right\}$. This condition does not imply an order on the alternatives 2 to 5 . We have to consider several sub-cases:

(4a) $u_{i, A}^{2}>\max \left\{u_{i, A}^{3}, u_{i, A}^{4}, u_{i, A}^{5}\right\}$. In this case, each investor selects either alternative 1 or alternative 2 or alternative 9 , i.e. we have to compare $u_{i, A}^{1}, u_{i, A}^{2}$ and $u_{i, A}^{9}$ :

$$
\begin{aligned}
& u_{i, A}^{1} \geq u_{i, A}^{2} \Leftrightarrow i \geq r_{A A}-p_{A} \equiv \alpha_{1} \\
& u_{i, A}^{1} \geq u_{i, A}^{9} \Leftrightarrow i \geq \frac{r_{A B}+1-r_{B B}-t-q-2 p_{B}}{2} \equiv \alpha_{8} \\
& u_{i, A}^{2} \geq u_{i, A}^{9} \Leftrightarrow i \geq r_{A B}+1-r_{B B}-r_{A A}-t-q-2 p_{B}+p_{A} \equiv \alpha_{9}
\end{aligned}
$$

Here, we have $\alpha_{1}+\alpha_{9}=2 \alpha_{8}$, i.e. $\alpha_{1}-\alpha_{8}=\alpha_{8}-\alpha_{9}$. We have to consider two sub-sub-cases:

(4a1) $\alpha_{1} \geq \alpha_{8}$, i.e. $\alpha_{1} \geq \alpha_{8} \geq \alpha_{9}$. Here, all investors $i \in\left[0, \alpha_{9}\right]$ choose alternative 9 , all investors $i \in\left[\alpha_{9}, \alpha_{1}\right]$ choose alternative 2 and all investors $i \in\left[\alpha_{1}, 1\right]$ choose alternative 1 . From this, we get the supply function for stock A and demand functions for stock B as follows:

$$
\begin{aligned}
& S_{A B}=\left\{\begin{array}{c}
0, \text { if } \alpha_{9}<0 \\
\alpha_{9}, \text { if } 0 \leq \alpha_{9} \leq 1, S_{A A}=\left\{\begin{array}{c}
\alpha_{1}-\alpha_{9}, \text { if } \alpha_{1}-\alpha_{9} \leq 1 \\
1, \text { if } \alpha_{1}-\alpha_{9}>1
\end{array}\right.
\end{array}\right. \\
& D_{B B}=\left\{\begin{array}{c}
0, \text { if } \alpha_{9}>1<0 \\
\alpha_{9}, \text { if } 0 \leq \alpha_{9} \leq 1, D_{B A}=0 \\
1, \text { if } \alpha_{9}>1
\end{array}\right.
\end{aligned}
$$

(4a2) $\alpha_{8} \geq \alpha_{1}$, i.e. $\alpha_{9} \geq \alpha_{8} \geq \alpha_{1}$. I.e. all investors $i \in\left[0, \alpha_{1}\right]$ choose alternative 9 , all investors $i \in\left[\alpha_{1}, \alpha_{8}\right]$ choose alternative 9 ; all investors $i \in\left[\alpha_{8}, \alpha_{9}\right]$ choose alternative 1 and all investors $i \in\left[\alpha_{9}, 1\right]$ choose alternative 1. From this, we get the supply function for stock A and demand functions for stock B as follows:

$$
\begin{aligned}
& S_{A B}=\left\{\begin{array}{c}
0, \text { if } \alpha_{8}<0 \\
\alpha_{8}, \text { if } 0 \leq \alpha_{8} \leq 1 \\
1, \text { if } \alpha_{8}>1
\end{array}, D_{B B}=\left\{\begin{array}{c}
0, \text { if } \alpha_{8}<0 \\
\alpha_{8}, \text { if } 0 \leq \alpha_{8} \leq 1 \\
1, \text { if } \alpha_{8}>1
\end{array}\right.\right. \\
& S_{A A}=0, D_{B A}=0
\end{aligned}
$$


The next three sub-cases are very similar:

(4b) $u_{i, A}^{3}>\max \left\{u_{i, A}^{2}, u_{i, A}^{4}, u_{i, A}^{5}\right\}$. We consider the following two subsub-cases:

(4b1) $\alpha_{6} \geq \alpha_{10} \equiv 1-r_{B B}-p_{B}$. We now get:

$$
\begin{aligned}
& S_{A B}=\left\{\begin{array}{c}
0, \text { if } \alpha_{6}<0 \\
\alpha_{6}, \text { if } 0 \leq \alpha_{6} \leq 1 \\
1, \text { if } \alpha_{6}>1
\end{array}, D_{B B}=\left\{\begin{array}{c}
0, \text { if } \alpha_{10}<0 \\
\alpha_{10}, \text { if } 0 \leq \alpha_{10} \leq 1 \\
1, \text { if } \alpha_{10}>1
\end{array}\right.\right. \\
& S_{A A}=0, D_{B A}=0
\end{aligned}
$$

(4b2) $\alpha_{10} \geq \alpha_{6}$. We get the same result as in case (4a2).

(4C) $u_{i, A}^{4}>\max \left\{u_{i, A}^{2}, u_{i, A}^{3}, u_{i, A}^{5}\right\}$. We consider the following two subsub-cases:

$(4 \mathrm{C} 1) \alpha_{3} \geq \alpha_{11} \equiv r_{A B}-r_{B B}-t-q-2 p_{B}+r_{B A}+p_{A}$. We get

$$
\begin{aligned}
& S_{A B}=\left\{\begin{array}{c}
0, \text { if } \alpha_{11}<0 \\
\alpha_{11}, \text { if } 0 \leq \alpha_{11} \leq 1, \\
1, \text { if } \alpha_{11}>1
\end{array}\right. \\
& D_{B B}=\left\{\begin{array}{c}
0, \text { if } \alpha_{11}<0 \\
\alpha_{11}, \text { if } 0 \leq \alpha_{11} \leq 1, D_{B A}=\left\{\begin{array}{c}
\alpha_{3}-\alpha_{11}, \text { if } \alpha_{3}-\alpha_{11} \leq 1 \\
1, \text { if } \alpha_{11}>1
\end{array}\right.
\end{array}\right.
\end{aligned}
$$

(4C2) $\alpha_{11} \geq \alpha_{3}$. We get the same result as in the cases (4a2) and (4b2).

(4d) $u_{i, A}^{5}>\max \left\{u_{i, A}^{2}, u_{i, A}^{3}, u_{i, A}^{4}\right\}$. We consider the following two subsub-cases:

(4d1) $\alpha_{5} \geq \alpha_{12} \equiv r_{A B}-q-p_{B}$. We get

$$
\begin{aligned}
& S_{A B}=\left\{\begin{array}{c}
0, \text { if } \alpha_{12}<0 \\
\alpha_{12}, \text { if } 0 \leq \alpha_{12} \leq 1 \\
1, \text { if } \alpha_{12}>1
\end{array}, D_{B B}=\left\{\begin{array}{c}
0, \text { if } \alpha_{5}<0 \\
\alpha_{5}, \text { if } 0 \leq \alpha_{5} \leq 1 \\
1, \text { if } \alpha_{5}>1
\end{array}\right.\right. \\
& S_{A A}=0, D_{B A}=0
\end{aligned}
$$

(4d2) $\alpha_{12} \geq \alpha_{5}$. We get the same result as in the cases (4a2), (4b2) and $(4 \mathrm{c} 2)$.

Finally, there are several other cases we do not discuss in details but which are important and have to be kept in mind. These are cases where all investors are indifferent between at least two alternatives from 6 to 9 (or from 2 to 5). If for example $u_{i, A}^{6}=u_{i, A}^{7}>\max \left\{u_{i, A}^{8}, u_{i, A}^{9}\right\}$, we find that the supply and demand may be given by any linear combination of the supply and demand functions of the cases (1) and (2). The findings for other cases are similar. 


\section{Appendix B}

Proof of propositions 1 and 2:

Proving these three proposition is very tedious, though not difficult. We therefore do not discuss the entire proof in details, but rather look at a few cases only. Other cases can be dealt with in a similar way. To derive the equilibrium stock prices and trading turnovers on the four stock markets, we have to consider again several cases. We first consider cases in which both stocks are traded:

(A) Assume that the conditions for case (1) in Appendix A are given, i.e. $u_{i, A}^{6}>\max \left\{u_{i, A}^{7}, u_{i, A}^{8}\right\}$. We find $S_{A A}=D_{B A} \geq 0$ and $S_{A B}=0$, $D_{B B}=0$. An equilibrium would require that country $B$ investors choose $D_{A A}=S_{B A} \geq 0$ and $D_{A B}=0, S_{B B}=0$. Immediate candidates for this are the following:

(A1) Analogous to case (4a2) above, we know: If $u_{i, B}^{9}>\max \left\{u_{i, B}^{6}, u_{i, B}^{7}, u_{i, B}^{8}\right\}$, $u_{i, B}^{2}>\max \left\{u_{i, B}^{3}, u_{i, B}^{4}, u_{i, B}^{5}\right\}$ and $\bar{\alpha}_{8} \geq \bar{\alpha}_{1}$, where $\bar{\alpha}_{1} \equiv r_{B B}-p_{B}$ and $\bar{\alpha}_{8} \equiv \frac{r_{B A}+1-r_{A A}-t-q-2 p_{A}}{2}$, then

$$
\begin{aligned}
& S_{B A}=\left\{\begin{array}{c}
0, \text { if } \bar{\alpha}_{8}<0 \\
\bar{\alpha}_{8}, \text { if } 0 \leq \bar{\alpha}_{8} \leq 1, D_{A A}=\left\{\begin{array}{c}
0, \text { if } \bar{\alpha}_{8}<0 \\
1, \text { if } \bar{\alpha}_{8}>1
\end{array} \bar{\alpha}_{8}, \text { if } 0 \leq \bar{\alpha}_{8} \leq 1\right. \\
1, \text { if } \bar{\alpha}_{8}>1
\end{array}\right. \\
& S_{B B}=0, D_{A B}=0
\end{aligned}
$$

An equilibrium would require $S_{A A}=D_{A A}$ and $D_{B A}=S_{B A}$. Note that

$$
\begin{aligned}
\alpha_{1} & =\bar{\alpha}_{8} \text { and } \alpha_{3}=\bar{\alpha}_{8} \\
& \Leftrightarrow \\
r_{A A} & =\frac{1}{2}-\frac{1}{4}(t+q), r_{B A}=\frac{1}{2}+\frac{1}{4}(t+q), \\
x_{A A} & =x_{B A}=\frac{1}{2}-\frac{1}{4}(t+q)-\left(p_{A}^{T}+p_{A}^{S}\right)
\end{aligned}
$$

This is an equilibrium if $\frac{1}{2}-\frac{1}{4}(t+q)-\left(p_{A}^{T}+p_{A}^{S}\right) \geq 0$ and for $r_{A A}=$ $\frac{1}{2}-\frac{1}{4}(t+q)$ and $r_{B A}=\frac{1}{2}+\frac{1}{4}(t+q)$ all conditions above are fulfilled. It is easy to show that this leads after a few considerations to the following result:

If

$$
\begin{aligned}
2-4\left(p_{A}^{T}+p_{A}^{S}\right) \geq & t+q \geq 2 q+\max \left\{0,4\left(p_{A}^{T}+p_{A}^{S}\right)-4\left(p_{B}^{T}+p_{B}^{S}\right)\right\} \\
& \text { then } \\
x_{A A}= & x_{B A}=\frac{1}{2}-\frac{1}{4}(t+q)-\left(p_{A}^{T}+p_{A}^{S}\right), x_{A B}=x_{B B}=0
\end{aligned}
$$

is an equilibrium 
(A2) Analogous to case (4b2) above, we know: If $u_{i, B}^{9}>\max \left\{u_{i, B}^{6}, u_{i, B}^{7}, u_{i, B}^{8}\right\}$, $u_{i, A}^{3}>\max \left\{u_{i, A}^{2}, u_{i, A}^{4}, u_{i, A}^{5}\right\}$ and $\bar{\alpha}_{10} \geq \bar{\alpha}_{6}$, where $\bar{\alpha}_{6}=r_{B A}-t-\left(q_{A}+\right.$ $\left.q_{B}\right)-\left(p_{A}^{T}+p_{A}^{S}\right)$ and $\bar{\alpha}_{10}=1-r_{A A}-\left(p_{A}^{T}+p_{A}^{S}\right)$, then

$$
\begin{aligned}
& S_{B A}=\left\{\begin{array}{c}
0, \text { if } \bar{\alpha}_{8}<0 \\
\bar{\alpha}_{8}, \text { if } 0 \leq \bar{\alpha}_{8} \leq 1 \\
1, \text { if } \bar{\alpha}_{8}>1
\end{array}, D_{A A}=\left\{\begin{array}{c}
0, \text { if } \bar{\alpha}_{8}<0 \\
\bar{\alpha}_{8}, \text { if } 0 \leq \bar{\alpha}_{8} \leq 1 \\
1, \text { if } \bar{\alpha}_{8}>1
\end{array}\right.\right. \\
& S_{B B}=0, D_{A B}=0
\end{aligned}
$$

An equilibrium would require $S_{A A}=D_{A A}$ and $D_{B A}=S_{B A}$. Note that

$$
\begin{aligned}
\alpha_{1} & =\bar{\alpha}_{8} \text { and } \alpha_{3}=\bar{\alpha}_{8} \\
& \Leftrightarrow \\
r_{A A} & =\frac{1}{2}-\frac{1}{4}(t+q), r_{B A}=\frac{1}{2}+\frac{1}{4}(t+q), \\
x_{A A} & =x_{B A}=\frac{1}{2}-\frac{1}{4}(t+q)-\left(p_{A}^{T}+p_{A}^{S}\right)
\end{aligned}
$$

This is an equilibrium if $\frac{1}{2}-\frac{1}{4}(t+q)-\left(p_{A}^{T}+p_{A}^{S}\right) \geq 0$ and for $r_{A A}=$ $\frac{1}{2}-\frac{1}{4}(t+q)$ and $r_{B A}=\frac{1}{2}+\frac{1}{4}(t+q)$ all conditions above (including the two conditions for case (1)) are fulfilled. However, the condition $r_{B A}-\left(q_{A}+q_{B}\right) \geq 1-r_{A A}$ implies $\left(q_{A}+q_{B}\right) \leq 0$ which is in general not possible.

(A3) Analogous to case (4c2) above, we consider the case that $u_{i, B}^{9}>$ $\max \left\{u_{i, B}^{6}, u_{i, B}^{7}, u_{i, B}^{8}\right\}, u_{i, A}^{4}>\max \left\{u_{i, A}^{2}, u_{i, A}^{3}, u_{i, A}^{5}\right\}$ and $\bar{\alpha}_{11} \geq \bar{\alpha}_{3}\left(\bar{\alpha}_{11}\right.$ and $\bar{\alpha}_{3}$ defined in a similar way as before) and find

$$
\begin{aligned}
& \text { If } \\
2-4\left(p_{A}^{T}+p_{A}^{S}\right) \geq & t+q \geq \max \left\{2 q, 2 q+4\left(p_{A}^{T}+p_{A}^{S}\right)-4\left(p_{B}^{T}+p_{B}^{S}\right),\right. \\
& \left.\frac{4}{3} q-\frac{2}{3}+\frac{4}{3}\left(p_{B}^{T}+p_{B}^{S}\right)-\frac{4}{3}\left(p_{A}^{T}+p_{A}^{S}\right)\right\} \\
& \text { then } \\
x_{A A}= & x_{B A}=\frac{1}{2}-\frac{1}{4}(t+q)-\left(p_{A}^{T}+p_{A}^{S}\right), x_{A B}=x_{B B}=0
\end{aligned}
$$

is an equilibrium

(A4) Analogous to case (4d2) above, we consider the case that $u_{i, B}^{9}>$ $\max \left\{u_{i, B}^{6}, u_{i, B}^{7}, u_{i, B}^{8}\right\}, u_{i, A}^{5}>\max \left\{u_{i, A}^{2}, u_{i, A}^{3}, u_{i, A}^{4}\right\}$ and $\bar{\alpha}_{12} \geq \bar{\alpha}_{5}\left(\bar{\alpha}_{12}\right.$ and 
$\bar{\alpha}_{5}$ defined in a similar way as before) and find

$$
\begin{aligned}
& \text { If } \\
\left(p_{B}^{T}+p_{B}^{S}\right) \geq & \left(p_{A}^{T}+p_{A}^{S}\right) \\
2 q \leq & t+q \leq \min \left\{2-4\left(p_{A}^{T}+p_{A}^{S}\right), \frac{4}{3} q+\frac{2}{3}+\frac{4}{3}\left(p_{B}^{T}+p_{B}^{S}\right)-\frac{4}{3}\left(p_{A}^{T}+p_{A}^{S}\right)\right\} \\
& \text { then } \\
x_{A A}= & x_{B A}=\frac{1}{2}-\frac{1}{4}(t+q)-\left(p_{A}^{T}+p_{A}^{S}\right), x_{A B}=x_{B B}=0 \\
& \text { is an equilibrium }
\end{aligned}
$$

Summary of the cases (A1) to (A4):

Comparing the results for the cases (A1), (A3) and (A4), we can easily see that the conditions given in (A1) are broader than those in (A3) and in (A4). I.e. we can summarize these results as follows:

If

$$
\begin{aligned}
2-4\left(p_{A}^{T}+p_{A}^{S}\right) \geq & t+q \geq 2 q+\max \left\{0,4\left(p_{A}^{T}+p_{A}^{S}\right)-4\left(p_{B}^{T}+p_{B}^{S}\right)\right\} \\
& \text { then } \\
x_{A A}= & x_{B A}=\frac{1}{2}-\frac{1}{4}(t+q)-\left(p_{A}^{T}+p_{A}^{S}\right), x_{A B}=x_{B B}=0 \\
& \text { is an equilibrium }
\end{aligned}
$$

(A5) Analogous to case (4b1) above, we consider $u_{i, B}^{9}>\max \left\{u_{i, B}^{6}, u_{i, B}^{7}, u_{i, B}^{8}\right\}$, $u_{i, A}^{3}>\max \left\{u_{i, A}^{2}, u_{i, A}^{4}, u_{i, A}^{5}\right\}$ and $\bar{\alpha}_{6} \geq \bar{\alpha}_{10}$ and find that $S_{A A}=D_{A A}$ and $D_{B A}=S_{B A}$ would imply $\bar{\alpha}_{6} \leq \bar{\alpha}_{10}$ which is in contradiction to the conditions for case (A5).

(A6) Analogous to case (4d1) above, we consider $u_{i, B}^{9}>\max \left\{u_{i, B}^{6}, u_{i, B}^{7}, u_{i, B}^{8}\right\}$, $u_{i, A}^{5}>\max \left\{u_{i, A}^{2}, u_{i, A}^{3}, u_{i, A}^{4}\right\}$ and $\bar{\alpha}_{5} \geq \bar{\alpha}_{12}$ and find

$$
\begin{aligned}
& \text { If } \\
& \begin{aligned}
t \leq & q \leq \min \left\{1-2\left(p_{A}^{T}+p_{A}^{S}\right), t+2\left(p_{B}^{T}+p_{B}^{S}\right)-2\left(p_{A}^{T}+p_{A}^{S}\right)\right\} \\
& \text { then } \\
x_{A A}= & \frac{1-t}{2}-\left(p_{A}^{T}+p_{A}^{S}\right), x_{B A}=\frac{1-q}{2}-\left(p_{A}^{T}+p_{A}^{S}\right), x_{A B}=x_{B B}=0 \\
& \text { is an equilibrium }
\end{aligned}
\end{aligned}
$$

(B) Assume that the conditions for case (2) of Appendix A and the analogous conditions for country $B$ investors are given, i.e. $u_{i, A}^{7}>$ $\max \left\{u_{i, A}^{6}, u_{i, A}^{8}, u_{i, A}^{9}\right\}$ and $u_{i, B}^{7}>\max \left\{u_{i, B}^{6}, u_{i, B}^{8}, u_{i, B}^{9}\right\}$. We find in a way 
similar to those used above

$$
\begin{aligned}
& \text { If } \\
t \leq & \min \left\{1-2\left(p_{A}^{T}+p_{A}^{S}\right), 1-2\left(p_{B}^{T}+p_{B}^{S}\right),\right. \\
& \left.q+2\left(p_{A}^{T}+p_{A}^{S}\right)-2\left(p_{B}^{T}+p_{B}^{S}\right), q+2\left(p_{B}^{T}+p_{B}^{S}\right)-2\left(p_{A}^{T}+p_{A}^{S}\right)\right\} \\
& \text { then } \\
x_{A A}= & \frac{1-t}{2}-\left(p_{A}^{T}+p_{A}^{S}\right), x_{B B}=\frac{1-t}{2}-\left(p_{B}^{T}+p_{B}^{S}\right), x_{A B}=x_{B A}=0 \\
& \text { is an equilibrium }
\end{aligned}
$$

(C) Assume that the conditions for case (3) of Appendix A and the analogous conditions for country $B$ investors are given, i.e. $u_{i, A}^{8}>$ $\max \left\{u_{i, A}^{6}, u_{i, A}^{7}, u_{i, A}^{9}\right\}$ and $u_{i, B}^{8}>\max \left\{u_{i, B}^{6}, u_{i, B}^{7}, u_{i, B}^{9}\right\}$. We find that this gives no equilibrium.

(D) Finally assume that the conditions for case (4) of Appendix A are given, i.e. $u_{i, A}^{9}>\max \left\{u_{i, A}^{6}, u_{i, A}^{7}, u_{i, A}^{8}\right\}$. This case is symmetric to case (A) above and leads to the following:

$$
\begin{aligned}
& \text { If } \\
2-4\left(p_{B}^{T}+p_{B}^{S}\right) \geq & t+q \geq 2 q+\max \left\{0,4\left(p_{B}^{T}+p_{B}^{S}\right)-4\left(p_{A}^{T}+p_{A}^{S}\right)\right\} \\
& \text { then } \\
x_{B B}= & x_{A B}=\frac{1}{2}-\frac{1}{4}(t+q)-\left(p_{B}^{T}+p_{B}^{S}\right), x_{B A}=x_{A A}=0 \\
& \text { is an equilibrium }
\end{aligned}
$$

If

$$
t \leq q \leq \min \left\{1-2\left(p_{B}^{T}+p_{B}^{S}\right), t+2\left(p_{A}^{T}+p_{A}^{S}\right)-2\left(p_{B}^{T}+p_{B}^{S}\right)\right\}
$$

then

$$
x_{B B}=\frac{1-t}{2}-\left(p_{B}^{T}+p_{B}^{S}\right), x_{A B}=\frac{1-q}{2}-\left(p_{B}^{T}+p_{B}^{S}\right), x_{B A}=x_{A A}=0
$$

is an equilibrium

Note that the conditions for the first sub-case in case (D) and those for the cases (A1) to (A4) overlap partially. The same holds for the conditions for the second sub-case in case (D) and those for case (A6). I.e. we may have multiple equilibria. In these cases, we apply or equilibrium refinement as described in section 3 . If $p_{A}<p_{B}$, we select the equilibrium described in (A1) to (A4) or (A6). If $p_{A}>p_{B}$, we select the equilibrium described in (D). If $p_{A}=p_{B}$, we select the allocation described in proposition 1 . It is easy to show that this is an equilibrium allocation though we have not discussed this equilibrium here.

It is easy to see that the results produced so far give us a proof of the propositions 1 and 2 . 
Proof of proposition 3:

(1) Assume $q \leq t$ and $p_{A}^{S}=p_{B}^{S}$. Note that under this assumption, $p_{A}^{T}=p_{B}^{T}>\frac{1}{2} c_{T}$ cannot be the case in equilibrium, because each exchange could do better by slightly decreasing its price and on that way attracting all the trade. Now assume $q \leq t$ and $p_{A}^{T}=p_{B}^{T}$. Note that $p_{A}^{S}=p_{B}^{S}$ implies

$$
\pi_{S}^{A}=\left[1-\frac{1}{2}(t+q)-2 p_{A}\right]\left[p_{A}^{S}-\frac{1}{2} c_{S}+\frac{1}{2} q_{A}-\frac{1}{2} c_{L}\right] \equiv \pi_{1}
$$

while $p_{A}^{S}<p_{B}^{S}$ implies

$$
\pi_{S}^{A}=\left[1-\frac{1}{2}(t+q)-2 p_{A}\right]\left[2 p_{A}^{S}-c_{S}+\frac{1}{2} q_{A}-\frac{1}{2} c_{L}\right] \equiv \pi_{2}
$$

I.e. $p_{A}^{S}=p_{B}^{S}>\frac{1}{2} c_{S}$ cannot be the case in equilibrium, because each CSD could do better by slightly decreasing its price and on that way attracting all the settlement of exchange trades. Thus, the following holds: If there is a symmetric equilibrium in which the link is used (and $p_{A}^{T}=p_{B}^{T} \geq \frac{1}{2} c_{T}, p_{A}^{S}=p_{B}^{S} \geq \frac{1}{2} c_{S}$ ), then it is characterized by $p_{A}^{T}=p_{B}^{T}=\frac{1}{2} c_{T}, p_{A}^{S}=p_{B}^{S}=\frac{1}{2} c_{S}$.

(2) Assume $p_{A}^{T}=p_{B}^{T}=\frac{1}{2} c_{T}, p_{A}^{S}=p_{B}^{S}=\frac{1}{2} c_{S}$ as given. Maximizing $\pi_{1}$ with respect to $q_{A}$ under the restriction $q \leq t$ and then assuming $q_{A}=q_{B}$ gives $q_{A}=q_{B}=\min \left\{\frac{1}{2} t ; \frac{2}{3} \beta+c_{L}\right\}$. Thus, the following holds: If there is a symmetric equilibrium in which the link is used, then it is characterized by $q_{A}=q_{B}=\min \left\{\frac{1}{2} t ; \frac{2}{3} \beta+c_{L}\right\}$. Note that $\frac{1}{2} t>\frac{2}{3} \beta+c_{L} \Leftrightarrow 4 \alpha<t-2 c_{L}$.

(3) We finally have to check under which conditions $p_{A}^{T}=p_{B}^{T}=\frac{1}{2} c_{T}$, $p_{A}^{S}=p_{B}^{S}=\frac{1}{2} c_{S}$ and $q_{A}=q_{B}=\min \left\{\frac{1}{2} t ; \frac{2}{3} \beta+c_{L}\right\}$ is indeed an equilibrium. It is clear that $p_{A}^{T}=\frac{1}{2} c_{T}$ is a best response of exchange $\mathrm{A}$ on $p_{B}^{T}=\frac{1}{2} c_{T}$, $p_{A}^{S}=p_{B}^{S}$ and $q \leq t$. Now we look at CSD A and assume $p_{A}^{T}=p_{B}^{T}=\frac{1}{2} c_{T}$, $p_{B}^{S}=\frac{1}{2} c_{S}$ and $q_{B}=\min \left\{\frac{1}{2} t ; \frac{2}{3} \beta+c_{L}\right\}$.

First assume $\frac{1}{2} t>\frac{2}{3} \beta+c_{L}$, i.e. $t-2 c_{L}>4 \alpha$. This implies $q_{B}=$ $\frac{2}{3} \beta+c_{L}$. Choosing $p_{A}^{S}=\frac{1}{2} c_{S}$ and $q_{A}=q_{B}$ would give $\pi_{S}^{A}=\frac{1}{9} \beta^{2}$. Now we show that no other strategy would give CSD A a higher profit.

(i) Alternatively, CSD A could choose a response characterized by $p_{A}^{S}<p_{B}^{S}$ and $q \leq t$. To find the best of such responses, we maximize $\pi_{S}^{A}$ under $p_{A}^{S}<p_{B}^{S}$ and $q \leq t$. This is the same as maximizing $\pi_{2}$ with respect to $q_{A}+4 p_{A}^{S}$ under $q_{A}+4 p_{A}^{S} \leq t-\frac{2}{3} \beta-c_{L}+2 c_{S}$. Maximizing $\pi_{2}$ without a constraint leads to the maximizer $q_{A}+4 p_{A}^{S}=\frac{2}{3} \beta+c_{L}+2 c_{S}$. This gives a profit of $\pi_{S}^{A}=\frac{1}{9} \beta^{2}$. Since the constrained maximization cannot lead to a higher profit, choosing a response characterized by $p_{A}^{S}<p_{B}^{S}$ and $q \leq t$ can never be better than choosing $p_{A}^{S}=\frac{1}{2} c_{S}$ and $q_{A}=q_{B}$.

(ii) Instead, CSD A could choose a response characterized by $p_{A}^{S}>p_{B}^{S}$ and $q \leq t$. We maximize $\pi_{S}^{A}$ under $p_{A}^{S}>p_{B}^{S}$ and $q \leq t$, which is the same 
as maximizing

$$
\pi_{S}^{A}=\left[1-\frac{1}{2}(t+q)-c_{S}-c_{T}\right]\left[\frac{1}{2} q_{A}-\frac{1}{2} c_{L}\right] \equiv \pi_{3}
$$

with respect to $q_{A}$ under $q_{A} \leq t-\frac{2}{3} \beta-c_{L}$. Maximizing $\pi_{3}$ without a constraint leads to the maximizer $q_{A}=\frac{2}{3} \beta+c_{L}$. This gives a profit of $\pi_{S}^{A}=\frac{1}{9} \beta^{2}$. Since the constrained maximization cannot lead to a higher profit, choosing a response characterized by $p_{A}^{S}>p_{B}^{S}$ and $q \leq t$ can never be better than choosing $p_{A}^{S}=\frac{1}{2} c_{S}$ and $q_{A}=q_{B}$.

(iii) Furthermore, CSD A could choose a response characterized by $\left|p_{A}^{S}-p_{B}^{S}\right| \leq \frac{1}{2}(q-t)$ and $q \geq t$. Maximizing $\pi_{S}^{A}$ under $\left|p_{A}^{S}-p_{B}^{S}\right| \leq \frac{1}{2}(q-t)$ and $q \geq t$, i.e. maximizing

$$
\pi_{S}^{A}=\left[1-t-c_{T}-2 p_{A}^{S}\right]\left[p_{A}^{S}-\frac{1}{2} c_{S}\right] \equiv \pi_{4}
$$

with respect to $p_{A}^{S}$ gives $p_{A}^{S}=\frac{1}{4}\left[1-t+c_{S}-c_{T}\right]$ and $\pi_{S}^{A}=\frac{1}{8} \alpha^{2}$. It is easy to see that $\frac{1}{8} \alpha^{2}<\frac{1}{9} \beta^{2}$ if $\frac{1}{2} t>\frac{2}{3} \beta+c_{L}$.

(iv) Next, CSD A could choose a response characterized by $p_{A}^{S}-p_{B}^{S} \geq$ $\frac{1}{2}(q-t)$ and $q \geq t$. Maximizing $\pi_{S}^{A}$ under $p_{A}^{S}-p_{B}^{S} \geq \frac{1}{2}(q-t)$ and $q \geq t$, i.e. maximizing

$$
\pi_{S}^{A}=\left[1-q-c_{S}-c_{T}\right]\left[\frac{1}{2} q_{A}-\frac{1}{2} c_{L}\right] \equiv \pi_{5}
$$

with respect to $q_{A}$ under $q_{A} \geq t-\frac{2}{3} \beta-c_{L}$ gives

$$
q_{A}=\left\{\begin{array}{l}
\frac{1}{6} \beta+\frac{1}{2} c_{L}+\frac{1}{4} t, \text { if } \frac{10}{9} \beta \geq t-2 c_{L} \\
t-c_{L}-\frac{2}{3} \beta, \text { if } \frac{10}{9} \beta \leq t-2 c_{L}
\end{array}\right.
$$

and

$$
\pi_{S}^{A}=\left\{\begin{array}{l}
\frac{1}{2}\left[\frac{1}{6} \beta+\frac{1}{4}\left(t-2 c_{L}\right)\right]^{2}, \text { if } \frac{10}{9} \beta \geq t-2 c_{L} \\
{\left[\beta-\frac{1}{2}\left(t-2 c_{L}\right)\right]\left[\frac{1}{2}\left(t-2 c_{L}\right)-\frac{1}{3} \beta\right], \text { if } \frac{10}{9} \beta \leq t-2 c_{L}}
\end{array}\right.
$$

It is easy to see that this is smaller than $\frac{1}{9} \beta^{2}$.

(v) Finally, CSD A could choose a response characterized by $p_{B}^{S}-$ $p_{A}^{S} \geq \frac{1}{2}(q-t)$ and $q \geq t$. We have to maximize $\pi_{S}^{A}$ under $p_{B}^{S}-p_{A}^{S} \geq \frac{1}{2}(q-t)$ and $q \geq t$, where

$$
\pi_{S}^{A}=\left[2-t-q-4 p_{A}\right]\left[p_{A}^{S}-\frac{1}{2} c_{S}\right]+\left[1-q-2 p_{A}\right]\left[\frac{1}{2} q_{A}-\frac{1}{2} c_{L}\right] \equiv \pi_{6}
$$

Unconstrained maximization leads to $p_{A}^{S}=\frac{1}{4}\left[1-t+c_{S}-c_{T}\right]>p_{B}^{S}=\frac{1}{2} c_{S}$ (and $q_{A}=\frac{1}{2} t-\frac{1}{3} \beta$ ), i.e. violates the constraints so that it is clear that at least on constraint must be binding. Maximizing under $p_{B}^{S}-p_{A}^{S}=\frac{1}{2}(q-t)$ 
again leads to $p_{A}^{S}=\frac{1}{4}\left[1-t+c_{S}-c_{T}\right]$, i.e. violates the constraint $q \geq t$. Maximizing under $q=t$ leads to $p_{A}^{S}=\frac{1}{3}-\frac{5}{12} t+\frac{1}{6} c_{S}-\frac{1}{3} c_{T}+\frac{1}{6} c_{L}$ which is smaller than $p_{B}^{S}=\frac{1}{2} c_{S}$ because $t-2 c_{L}>4 \alpha$. I.e. this is the maximizer of $\pi_{S}^{A}$ under $p_{B}^{S}-p_{A}^{S} \geq \frac{1}{2}(q-t)$ and $q \geq t$, and the maximum is given by $\pi_{S}^{A}=\frac{1}{9} \beta^{2}$.

This concludes the proof of part (1) of the proposition.

Now assume $\frac{1}{2} t<\frac{2}{3} \beta+c_{L}$, i.e. $t-2 c_{L}<4 \alpha$. This implies $q_{B}=\frac{1}{2} t$. Choosing $p_{A}^{S}=\frac{1}{2} c_{S}$ and $q_{A}=q_{B}$ would give $\pi_{S}^{A}=\frac{1}{4} \alpha\left[t-2 c_{L}\right]$. Again, we show that no other strategy would give CSD A a higher profit.

(i) CSD A could alternatively choose a response characterized by $p_{A}^{S}<p_{B}^{S}$ and $q \leq t$. To find the best of such responses, we maximize $\pi_{S}^{A}$ under $p_{A}^{S}<p_{B}^{S}$ and $q \leq t$, i.e. maximizing $\pi_{2}$ with respect to $q_{A}+4 p_{A}^{S}$ under $q_{A}+4 p_{A}^{S} \leq \frac{1}{2} t+2 c_{S}$. Unconstrained maximization leads to $q_{A}+$ $4 p_{A}^{S}=1-\frac{3}{4} t-c_{T}+c_{S}+\frac{1}{2} c_{L}$ which is greater than $\frac{1}{2} t+2 c_{S}$, because $t-2 c_{L}<4 \alpha$. I.e. the maximizer is $q_{A}+4 p_{A}^{S}=\frac{1}{2} t+2 c_{S}$ and the maximum is $\pi_{S}^{A}=\frac{1}{4} \alpha\left[t-2 c_{L}\right]$. Thus, choosing a response characterized by $p_{A}^{S}<p_{B}^{S}$ and $q \leq t$ can never be better than choosing $p_{A}^{S}=\frac{1}{2} c_{S}$ and $q_{A}=q_{B}$.

(ii) Next, CSD A could choose a response characterized by $p_{A}^{S}>p_{B}^{S}$ and $q \leq t$. We maximizing $\pi_{S}^{A}$ under $p_{A}^{S}>p_{B}^{S}$ and $q \leq t$, i.e. $\pi_{3}$ with respect to $q_{A}$ under $q_{A} \leq \frac{1}{2} t$. Unconstrained maximization leads to $q_{A}=1-\frac{3}{4} t-c_{T}-c_{S}+\frac{1}{2} c_{L}$ which is greater than $\frac{1}{2} t$, because $t-2 c_{L}<4 \alpha$. I.e. the maximizer is $q_{A}=\frac{1}{2} t$ and the maximum is $\pi_{S}^{A}=\frac{1}{4} \alpha\left[t-2 c_{L}\right]$. Thus, choosing a response characterized by $p_{A}^{S}>p_{B}^{S}$ and $q \leq t$ can never be better than choosing $p_{A}^{S}=\frac{1}{2} c_{S}$ and $q_{A}=q_{B}$.

(iii) Furthermore, CSD A could choose a response characterized by $\left|p_{A}^{S}-p_{B}^{S}\right| \leq \frac{1}{2}(q-t)$ and $q \geq t$. Maximizing $\pi_{S}^{A}$ under $\left|p_{A}^{S}-p_{B}^{S}\right| \leq \frac{1}{2}(q-t)$ and $q \geq t$, i.e. maximizing $\pi_{4}$ with respect to $p_{A}^{S}$ gives $\pi_{S}^{A}=\frac{1}{8} \alpha^{2}$. Since $\frac{1}{8} \alpha^{2} \leq \frac{1}{4} \alpha\left[t-2 c_{L}\right] \Leftrightarrow \frac{1}{2} \alpha \leq t-2 c_{L}$, we know now that $p_{A}^{T}=p_{B}^{T}=\frac{1}{2} c_{T}$, $p_{A}^{S}=p_{B}^{S}=\frac{1}{2} c_{S}, q_{A}=q_{B}=\frac{1}{2} t$ can be an equilibrium only if $\frac{1}{2} \alpha \leq t-2 c_{L}$.

(iv) Instead, it could choose a response characterized by $p_{A}^{S}-p_{B}^{S} \geq$ $\frac{1}{2}(q-t)$ and $q \geq t$. Maximizing $\pi_{S}^{A}$ under $p_{A}^{S}-p_{B}^{S} \geq \frac{1}{2}(q-t)$ and $q \geq t$, i.e. maximizing $\pi_{5}$ with respect to $q_{A}$ under $q_{A} \geq \frac{1}{2} t$ gives

$$
q_{A}=\left\{\begin{array}{l}
\frac{1}{2} \alpha+\frac{1}{4} t+\frac{1}{2} c_{L}, \text { if } 2 \alpha \geq t-2 c_{L} \\
\frac{1}{2} t, \text { if } 2 \alpha \leq t-2 c_{L}
\end{array}\right.
$$

and

$$
\pi_{S}^{A}=\left\{\begin{array}{l}
\frac{1}{8}\left[\alpha+\frac{1}{2} t-c_{L}\right]^{2}, \text { if } 2 \alpha \geq t-2 c_{L} \\
\frac{1}{4} \alpha\left[t-2 c_{L}\right], \text { if } 2 \alpha \leq t-2 c_{L}
\end{array}\right.
$$

It is easy to see that $\frac{1}{8}\left[\alpha+\frac{1}{2} t-c_{L}\right]^{2}$ is greater than $\frac{1}{4} \alpha\left[t-2 c_{L}\right]$, i.e. we know now that $p_{A}^{T}=p_{B}^{T}=\frac{1}{2} c_{T}, p_{A}^{S}=p_{B}^{S}=\frac{1}{2} c_{S}, q_{A}=q_{B}=\frac{1}{2} t$ can be an equilibrium only if $2 \alpha \leq t-2 c_{L}$. 
(v) Finally, CSD A could choose a response characterized by $p_{B}^{S}-$ $p_{A}^{S} \geq \frac{1}{2}(q-t)$ and $q \geq t$. Now, we have to maximize $\pi_{S}^{A}$ under $p_{B}^{S}-p_{A}^{S} \geq$ $\frac{1}{2}(q-t)$ and $q \geq t$, where $\pi_{S}^{A}=\pi_{6}$. Unconstrained maximization leads to $p_{A}^{S}=\frac{1}{4}\left[1-t+c_{S}-c_{T}\right]$ (and $q_{A}=\frac{1}{4} t+\frac{1}{2} c_{L}$ ), i.e. to $p_{B}^{S}-p_{A}^{S}<0$ so that it is clear that at least on constraint must be binding. Maximizing under $p_{B}^{S}-p_{A}^{S}=\frac{1}{2}(q-t)$ leads to $p_{A}^{S}=\frac{1}{4}\left[1-t+c_{S}-c_{T}\right]$, i.e. to $p_{B}^{S}-p_{A}^{S}<0$ so that $p_{B}^{S}-p_{A}^{S} \geq \frac{1}{2}(q-t)$ cannot be the only binding constraint. Maximizing under $q=t$ leads to $p_{A}^{S}=\frac{1}{4}-\frac{5}{16} t+\frac{1}{4} c_{S}-\frac{1}{4} c_{T}+\frac{1}{8} c_{L}$, which is greater than $p_{B}^{S}=\frac{1}{2} c_{S}$ because $t-2 c_{L}<4 \alpha$. I.e. the maximizer of $\pi_{S}^{A}$ under $p_{B}^{S}-p_{A}^{S} \geq \frac{1}{2}(q-t)$ and $q \geq t$ is $q=t$ and $p_{A}^{S}=\frac{1}{2} c_{S}$. The maximum is given by $\pi_{S}^{A}=\frac{1}{4} \alpha\left[t-2 c_{L}\right]$.

This concludes the proof of part (2) of the proposition.

Proof of proposition 4:

(1) Maximizing $\pi_{A}^{T}$ under $\left|p_{A}-p_{B}\right| \leq \frac{1}{2}(q-t)$ and assuming that $q \geq t$ gives $p_{A}^{T}=\frac{1}{4}\left[1-t+c_{T}-2 p_{A}^{S}\right]$. Maximizing $\pi_{A}^{S}$ under $\left|p_{A}-p_{B}\right| \leq \frac{1}{2}(q-t)$ and $q \geq t$ gives $p_{A}^{S}=\frac{1}{4}\left[1-t+c_{S}-2 p_{A}^{T}\right]$. Solving $p_{A}^{T}=\frac{1}{4}\left[1-t+c_{T}-2 p_{A}^{S}\right]$ and $p_{A}^{S}=\frac{1}{4}\left[1-t+c_{S}-2 p_{A}^{T}\right]$ gives $p_{A}^{T}=\frac{1}{6}\left(1-t-c_{S}+2 c_{T}\right), p_{A}^{S}=$ $\frac{1}{6}\left(1-t-c_{T}+2 c_{S}\right)$. I.e. if there is a symmetric equilibrium in which the link is not used, then it is characterized by $p_{A}^{T}=p_{B}^{T}=\frac{1}{6}\left(1-t-c_{S}+2 c_{T}\right)$ and $p_{A}^{S}=p_{B}^{S}=\frac{1}{6}\left(1-t-c_{T}+2 c_{S}\right)$. We now only need to check under which conditions this is indeed an equilibrium.

(2) Assume $q \geq t, p_{B}^{T}=\frac{1}{6}\left(1-t-c_{S}+2 c_{T}\right)$ and $p_{A}^{S}=p_{B}^{S}=\frac{1}{6}(1-t-$ $\left.c_{T}+2 c_{S}\right)$. If exchange $\mathrm{A}$ chooses $p_{A}^{T}=\frac{1}{6}\left(1-t-c_{S}+2 c_{T}\right)$, it achieves a profit of $\pi_{A}^{T}=\frac{1}{18} \alpha^{2}$. Alternatively, exchange $\mathrm{A}$ could choose a response characterized by $p_{B}-p_{A} \geq \frac{1}{2}(q-t)$. However, if $q$ is sufficiently high, this cannot lead to a profit higher than $\frac{1}{18} \alpha^{2}$.

(3) Assume $p_{A}^{T}=p_{B}^{T}=\frac{1}{6}\left(1-t-c_{S}+2 c_{T}\right), p_{B}^{S}=\frac{1}{6}\left(1-t-c_{T}+2 c_{S}\right)$ and some $q_{B} \geq \frac{1}{2} t$. If CSD A chooses $p_{A}^{S}=\frac{1}{6}\left(1-t-c_{T}+2 c_{S}\right)$ and $q_{A}=q_{B}$, then it achieves a profit of $\pi_{A}^{S}=\frac{1}{18} \alpha^{2}$. Alternatively, it could choose other responses. However, which responses are possible depends on $q_{B}$. If for example $q_{B}>t$, CSD A cannot choose a response that is characterized by $q \leq t$. Furthermore, if $q_{B}$ is sufficiently large, it is clear that choosing a response characterized by $p_{B}-p_{A} \geq \frac{1}{2}(q-t)$ cannot lead to a higher profit than $\frac{1}{18} \alpha^{2}$. Similarly, if $q_{B}$ is sufficiently large, it is clear that choosing a response characterized by $p_{A}-p_{B} \geq \frac{1}{2}(q-t)$ cannot lead to a higher profit than $\frac{1}{18} \alpha^{2}$ because such a response would imply that CSD A does not settle exchange trades but makes profit only from the link which is hardly used because $q$ is high. Thus, it is clear that there always exist a number $f$ such that all constellations with $p_{A}^{T}=p_{B}^{T}=\frac{1}{6}\left(1-t-c_{S}+2 c_{T}\right), p_{A}^{S}=p_{B}^{S}=\frac{1}{6}\left(1-t-c_{T}+2 c_{S}\right)$ and $q_{A}=q_{B} \geq f$ are equilibria in which the link is not used. 
Proof of proposition 5:

The proof is very similar to that of proposition 3 and therefore omitted.

Proof of proposition 6 :

The proof is very similar to that of proposition 4 and therefore omitted.

Proof of proposition \%:

(1) We first determine the best response of the operator of the CSDs on $p_{A}^{T}=p_{B}^{T}$ (under the constraint $p_{A}^{S}=p_{B}^{S}$ ):

We first maximize $\pi_{S}$ under the constraint $q \leq t$. Here, we have

$$
\pi_{S}=\left[\frac{1}{2}-\frac{1}{4} t-\frac{1}{4}\left(q+4 p_{A}^{S}\right)-p_{A}^{T}\right]\left[q+4 p_{A}^{S}-2 c_{S}-2 c_{L}\right]
$$

Maximizing with respect to $q+4 p_{A}^{S}$ gives $q+4 p_{A}^{S}=1-\frac{1}{2} t+c_{S}+c_{L}-2 p_{A}^{T}$ and

$$
\pi_{S}=\frac{1}{4}\left[1-\frac{1}{2} t-c_{S}-c_{L}-2 p_{A}^{T}\right]^{2} \equiv \pi_{S}^{1}
$$

We now maximize $\pi_{S}$ under the constraint $q \geq t$. We have

$$
\pi_{S}=\left[1-t-2 p_{A}^{S}-2 p_{A}^{T}\right]\left[2 p_{A}^{S}-c_{S}\right]
$$

Maximizing with respect to $p_{A}^{S}$ gives $p_{A}^{S}=\frac{1}{4}\left[1-t+c_{S}-2 p_{A}^{T}\right]$ and

$$
\pi_{S}=\frac{1}{4}\left[1-t-c_{S}-2 p_{A}^{T}\right]^{2} \equiv \pi_{S}^{2}
$$

Now note that $\pi_{S}^{1}>\pi_{S}^{2} \Leftrightarrow t>2 c_{L}$. With that we get the following result:

If $t>2 c_{L}$, we get as best responses all strategies that are characterized by $q+4 p_{A}^{S}=1-\frac{1}{2} t+c_{S}+c_{L}-2 p_{A}^{T}$ and $q \leq t$.

If $t<2 c_{L}$, we get as best responses all strategies that are characterized by $p_{A}^{S}=\frac{1}{4}\left[1-t+c_{S}-2 p_{A}^{T}\right]$ and $q \geq t$.

(2) We now prove part (1) of the proposition:

If $q \leq t$, the exchanges enter into perfect Bertrand competition that leads to $p_{A}^{T}=p_{B}^{T}=\frac{1}{2} c_{T}$. I.e. if there is a symmetric equilibrium with trade that is characterized by $q \leq t$, then it is characterized by $p_{A}^{T}=p_{B}^{T}=$ $\frac{1}{2} c_{T}$. Assume $t>2 c_{L}$. The best response of the operator of the CSDs on $p_{A}^{T}=p_{B}^{T}=\frac{1}{2} c_{T}$ is according to (1) given by $q+4 p_{A}^{S}=1-\frac{1}{2} t+c_{S}+c_{L}-c_{T}$ and $q \leq t$. Finally, it is easy to check that $p_{A}^{T}=\frac{1}{2} c_{T}$ is a best response of exchange $A$ on $q+4 p_{A}^{S}=1-\frac{1}{2} t+c_{S}+c_{L}-c_{T}, q \leq t$ and $p_{B}^{T}=\frac{1}{2} c_{T}$. 
(3) We now prove part (2) of the proposition.

Assume $q \geq t$ and some strategies $p_{B}^{T}$ and $p_{A}^{S}=p_{B}^{S}$. As long as $\left|p_{A}^{T}-p_{B}^{T}\right| \leq \frac{1}{2}(q-t)$, we have

$$
\pi_{A}^{T}=\left[1-t-2 p_{A}^{T}-2 p_{A}^{S}\right]\left[p_{A}^{T}-\frac{1}{2} c_{T}\right] \equiv \pi_{A}^{T, 1}
$$

I.e. maximizing $\pi_{A}^{T}$ and then setting $p_{A}^{T}=p_{B}^{T}$ is the same as maximizing $\pi_{A}^{T, 1}$ which gives $p_{A}^{T}=\frac{1}{4}\left[1-t+c_{T}-2 p_{A}^{S}\right]$. I.e. if there is a symmetric equilibrium that is characterized by $q \geq t$, then it is characterized by $p_{A}^{T}=p_{B}^{T}=\frac{1}{4}\left[1-t+c_{T}-2 p_{A}^{S}\right]$. Now assume $t<2 c_{L}$. We know from (1) that if there exists a symmetric equilibrium, it is characterized by $p_{A}^{S}=$ $\frac{1}{4}\left[1-t+c_{S}-2 p_{A}^{T}\right]$ and $q \geq t$. I.e. we know that if there is a symmetric equilibrium, it is characterized by $p_{A}^{T}=p_{B}^{T}=\frac{1-t+2 c_{T}-c_{S}}{6}, p_{A}^{S}=$ $p_{B}^{S}=\frac{1-t+2 c_{S}-c_{T}}{6}, q \geq t$.

To conclude the proof, we only have to show that exchange A cannot do better by deviating from $p_{A}^{T}=\frac{1-t+2 c_{T}-c_{S}}{6}$, if $p_{B}^{T}=\frac{1-t+2 c_{T}-c_{S}}{6}$ and $p_{A}^{S}=p_{B}^{S}=\frac{1-t+2 c_{S}-c_{T}}{6}$ if $q \geq h$ for some $h \geq t$. However, this is immediate since the only potential better response would be to select a response characterized by $p_{B}^{T}-p_{A}^{T} \geq \frac{1}{2}(q-t)$. But if $q$ is sufficiently high, this would require a very small $p_{A}^{T}$ which may even lead to a negative profit for exchange A.

Proof of proposition 9:

The proof is very simple and therefore omitted.

Proof of theorem 10:

The proof is straightforward and therefore omitted.

\section{References}

[1] De Noia, C. (1998), 'Competition and Integration among Stock Exchanges in Europe: Network Effects, Implicit Mergers and Remote Access', The Wharton School Discussion Paper 98-03.

[2] Domowitz, I. (1995), 'Electronic Derivatives Exchanges: Implicit Mergers, Network Externalities and Standardization', Quarterly Review of Economics and Finance, p. 163.

[3] Economides, N. (1996), 'The Economics of Networks,' International Journal of Industrial Organization, vol. 16, no. 4, p675-699.

[4] Economides, N. (2003), 'Competition Policy in Network Industries: An Introduction,' Stern Business School, New York University, mimeo. 
[5] Economides, N. and Schwartz, R. (1995), 'Electronic Call Market Trading,' Journal of Portfolio Management, vol. 21, no. 3, p10-18.

[6] Holthausen, C. and Tapking, J. (2003), 'Raising Rival's Costs in the Securities Settlement Industry', ECB Discussion Paper, forthcoming.

[7] Kauko, K. (2003), 'Interlinking Securities Settlement Systems: A Strategic Commitment?' , Bank of Finland Discussion Paper, 262003.

[8] Koppl, T., and Monnet, C. (2003), 'Guess What: It's the Settlements!', ECB, mimeo.

[9] Laffont, J. and Tirole, J. (1996), 'Creating Competition through Interconnection: Theory and Practice', Journal of Regulatory Economics, 10, 227-256.

[10] Laffont, Rey and Tirole (1998a), 'Network competition I: Overview and non-discriminatory pricing', Rand Journal of Economics, 29(1), $1-37$.

[11] Laffont, Rey and Tirole (1998b), 'Network competition II: Price discrimination', Rand Journal of Economics, 29(1), 38-56.

[12] Perry, M (1989), 'Vertical integration', in: R. Schmalensee and R. Willig (eds.), Handbook of Industrial Organisation, Amsterdam: North Holland.

[13] Schmiedel, H., Malkamaki, M., and Tarkka, J. (2002), Economies of Scale and Technological Development in Securities Depository and Settlement Systems, Bank of Finland Discussion Paper, 26-2002.

[14] Shy, O. (1996), 'Industry Organization', The MIT Press, Cambridge Mass., London, 1996.

[15] Shy, O. and Tarkka, J. (2001), 'Stock Exchange Alliances, Access Fees and Competition', Bank of Finland Discussion Paper, 22/2001

[16] Tirole, J.(1988), The Theory of Industrial Organization. MIT Press, Cambridge Mass., London, 1988.

[17] Vickers, J. (1995), 'Competition and Regulation in Vertically Related Markets', Review of Economic Studies 62, 1-17. 


\section{European Central Bank working paper series}

For a complete list of Working Papers published by the ECB, please visit the ECB's website (http://www.ecb.int).

354 "Taking stock: monetary policy transmission to equity markets" by M. Ehrmann and M. Fratzscher, May 2004.

355 "Production interdependence and welfare" by K. X. D. Huang and Z. Liu, May 2004.

356 "Developing a euro area accounting matrix: issues and applications" by T. Jellema, S. Keuning, P. McAdam and R. Mink, May 2004.

357 "Seasonal adjustment and the detection of business cycle phases" by A. M. Mir and D. R. Osborn, May 2004.

358 "Did the pattern of aggregate employment growth change in the euro area in the late 1990s?" by G. Mourre, May 2004.

359 "The longer term refinancing operations of the ECB" by T. Linzert, D. Nautz and U. Bindseil, May 2004.

360 "Optimal monetary policy rules for the euro area: an analysis using the area wide model" by A. Dieppe, K. Küster and P. McAdam, May 2004.

361 "Excess reserves and the implementation of monetary policy of the ECB" by U. Bindseil, G. Camba-Mendez, A. Hirsch and B. Weller, May 2004.

362 "Oil price shocks and real GDP growth: empirical evidence for some OECD countries" by R. Jiménez-Rodríguez and M. Sánchez, May 2004.

363 "Communication and exchange rate policy" by M. Fratzscher, May 2004.

364 “Asset price booms and monetary policy" by C. Detken and F. Smets, May 2004.

365 "Exchange rates and fundamentals: new evidence from real-time data" by M. Ehrmann and M. Fratzscher, May 2004.

366 "The informational content of over-the-counter currency options" by P. Christoffersen and S. Mazzotta, June 2004.

367 "Factor substitution and factor augmenting technical: progress in the US: a normalized supply-side system approach" by R. Klump, P. McAdam and A. Willman, June 2004.

368 "Capital quality improvement and the sources of growth in the euro area" by P. Sakellaris and F. W. Vijselaar, June 2004.

369 "Sovereign risk premia in the European government bond market" by K. Bernoth, J. von Hagen and L. Schuknecht, June 2004.

370 "Inflation persistence during periods of structural change: an assessment using Greek data" by G. Hondroyiannis and S. Lazaretou, June 2004.

37I “Inflation persistence: facts or artefacts?” by C. R. Marques, June 2004.

372 "The operational target of monetary policy and the rise and fall of reserve position doctrine" by U. Bindseil, June 2004. 
373 "Technology shocks and robust sign restrictions in a euro area SVAR" by G. Peersman and R. Straub, July 2004.

374 "To aggregate or not to aggregate? Euro area inflation forecasting" by N. Benalal, J. L. Diaz del Hoyo, B. Landau, M. Roma and F. Skudelny, July 2004.

375 “Guess what: it's the settlements!” by T. V. Koeppl and C. Monnet, July 2004.

376 "Raising rival's costs in the securities settlement industry" by C. Holthausen and J. Tapking, July 2004.

377 "Optimal monetary policy under commitment with a zero bound on nominal interest rates" by K. Adam and R. M. Billi, July 2004.

378 "Liquidity, information, and the overnight rate" by C. Ewerhart, N. Cassola, S. Ejerskov and N. Valla, July 2004.

379 "Do financial market variables show (symmetric) indicator properties relative to exchange rate returns?" by O. Castrén, July 2004.

380 "Optimal monetary policy under discretion with a zero bound on nominal interest rates" by K. Adam and R. M. Billi, August 2004.

38 I "Fiscal rules and sustainability of public finances in an endogenous growth model" by B. Annicchiarico and N. Giammarioli, August 2004.

382 "Longer-term effects of monetary growth on real and nominal variables, major industrial countries, 1880-200I" by A. A. Haug and W. G. Dewald, August 2004.

383 "Explicit inflation objectives and macroeconomic outcomes" by A. T. Levin, F. M. Natalucci and J. M. Piger, August 2004.

384 "Price rigidity. Evidence from the French CPI micro-data" by L. Baudry, H. Le Bihan, P. Sevestre and S. Tarrieu, August 2004.

385 "Euro area sovereign yield dynamics: the role of order imbalance" by A. J. Menkveld, Y. C. Cheung and F. de Jong, August 2004.

386 "Intergenerational altruism and neoclassical growth models" by P. Michel, E. Thibault and J.-P. Vidal, August 2004.

387 "Horizontal and vertical integration in securities trading and settlement" by J. Tapking and J. Yang, August 2004. 
